\title{
COMPUTATIONAL MODEL OF ALENDRONATE EFFECTS ON CANINE RIB REMODELING AND MICRODAMAGE
}

\author{
A Thesis \\ Presented to the Faculty of \\ California Polytechnic State University \\ San Luis Obispo
}

\author{
In Partial Fulfillment of the \\ Requirements for the Degree \\ Master of Science in Engineering \\ with a Specialization in Biomedical Engineering
}

by

Emily Huang

September 2009 
(C) 2009

Emily Huang

ALL RIGHTS RESERVED 


\section{COMMITTEE MEMBERSHIP}

TITLE: $\quad$ Computational Model of Alendronate Effects on Canine Rib Remodeling and Microdamage

AUTHOR: Emily Huang

DATE SUBMITTED: $\quad$ September 2009

COMMITTEE CHAIR: Dr. Scott Hazelwood, Assistant Professor

COMMITTEE MEMBER: $\quad$ Dr. Lanny Griffin, Department Chair

COMMITTEE MEMBER: $\quad$ Dr. Kristen Cardinal, Assistant Professor 


\section{ABSTRACT \\ COMPUTATIONAL MODEL OF ALENDRONATE EFFECTS ON CANINE RIB REMODELING AND MICRODAMAGE}

\section{Emily Huang}

Bisphosphonates are a class of drugs used to prevent and treat bone diseases by inhibiting the resorption of bone by osteoclasts and suppressing bone remodeling. Osteoporosis is a bone disease that develops when bone resorption exceeds bone formation which results in an increase in bone porosity and fracture risk. The risk for fractures can be reduced by increasing bone mass. Alendronate is type of bisphosphonate that is approved by the Food and Drug Administration (FDA) to treat postmenopausal osteoporosis by suppressing basic multicellular unit (BMU) remodeling and increasing bone mass. The long term effects of bisphosphonates are still unclear due to the difficulty in obtaining long term data; therefore, developing a mathematical model based on data and relationships from short term studies can be a useful method in predicting the effects of the drug.

The purpose of this study was to develop a computer model that could simulate the long term effects of alendronate treatment on canine rib remodeling, bone volume, and microdamage by matching 1 and 3 year experimental data results. The experimental effects of alendronate (ALN) were studied at the Indiana University School of Medicine. In two separate experiments, skeletally mature female beagles were subjected to 1 and 3 year treatments of saline vehicle (CON), or one of two doses of ALN (ALN0.2 or ALN1.0 mg/kg/day). The lower dose (ALN0.2) corresponds to the clinical dosage used 
to treat postmenopausal osteoporosis and the higher dose (ALN1.0) is the dose used to treat Paget's disease. Bone volume fraction (BV/TV), damage, and remodeling activation frequency (Ac.f) of the rib were quantified using standard histomorphometric techniques.

The mathematical model was developed by modifying a previous mathematical algorithm for trabecular bone remodeling, to create an equilibrium for cortical bone remodeling that matched the experimental control data from 1 year studies. Using the equilibrium conditions as a baseline model, ALN was modeled by suppressing activation frequency and reducing the resorption area. The changes in BV/TV, damage accumulation, and Ac.f were followed for 3 years and compared to the experimental results. The results for BV/TV, Ac.f, and damage for the 1 year model and the results for BV/TV and damage for the 3 year model were consistent with experimental studies. $\mathrm{BV} / \mathrm{TV}$ results for both doses showed increases from 1 to 3 years with alendronate treatment. Ac.f results for both treatment doses at 1 year and ALN1.0 at 3 years were also within range of the experimental data; however, ALN0.2 for 3 years was not consistent with the experimental results. While the predicted Ac.f for ALN0.2 does show an initial decrease, it is not nearly as extreme as the results from the experimental data and the data remains fairly constant between 1 and 3 years, which is in contrast to the experimental results. The model also predicts damage accumulation is greatest early during bisphosphonate treatment, due to the initial suppression of bone resorption. This increase in microdamage accumulation was previously thought to impair the mechanical properties of bone; however, recent experimental studies show that while the initial increase in microdamage may contribute to alterations in bone properties at 1 year of 
treatment, other factors appear to contribute to their reduction long term. The simulation results are consistent with the experimental data, which suggest that damage increases for up to 1 year of treatment and then levels off thereafter. The results of the simulation suggest that since bisphosphonates do not cause further increases in microdamage accumulation after 1 year of treatment, ALN may not lead to increased bone fragility associated with microdamage long term and rather, may decrease fracture risk. 


\section{ACKNOWLEDGMENTS}

I would like to thank all the people who have assisted me during my master study.

I would especially like to show my appreciation to my advisor, Dr. Scott Hazelwood, for his guidance and patience during my research. Thank you for giving me the opportunity to work on this project.

I would also like to thank my committee members, Dr. Lanny Griffin and Dr. Kristen Cardinal for providing me with assistance. Dr. Griffin, for his help in teaching me how to use Bioquant and Dr. Cardinal, for directing me when I needed help on statistics and for helping me look for a thesis project.

I am thankful to Daniel Hale for taking his time to teach me how to cut and mount the bone samples for histological analysis. I would also like to thank Chase Fetzer for his help in using Bioquant.

And to my parents and sister, I would like to thank you for your love and support throughout my life. Thank you for providing me with the opportunity and the motivation to achieve everything that I have.

This project was supported in part by NIH Grants AR51555 and Merck and Co. kindly provided the alendronate for the project to the Indiana University School of Medicine. 


\section{TABLE OF CONTENTS}



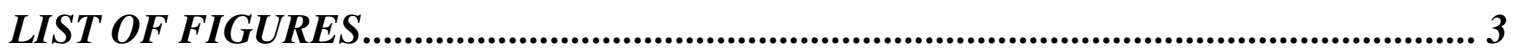



1.1 Properties of Bone .......................................................................................................................................... 4



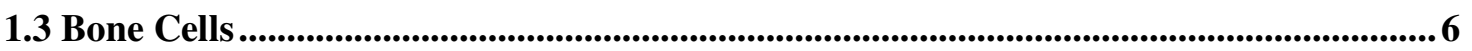

1.4 Bone Modeling and Remodeling .....................................................................................8



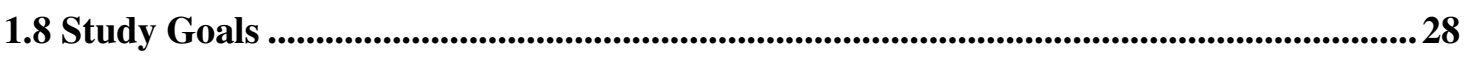

CHAPTER 2: MATERIALS AND METHODS .................................................... 31

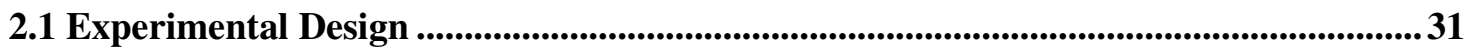

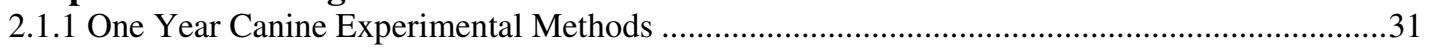

2.1.2 Three Year Canine Experimental Methods ...............................................................................

2.2 Sample Preparation................................................................................................................................... 34

2.3 Histomorphometric Analysis ....................................................................................................35

2.4 Remodeling Simulation ..............................................................................................................36

2.5 Statistical Analysis.......................................................................................................................4 47

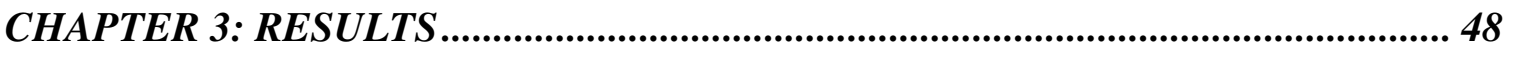

3.1 Experimental Bone Volume Fraction Measurements ..................................................48

3.3 Simulation Activation Frequency Results .........................................................52

3.4 Simulation Microdamage Results ...........................................................................5

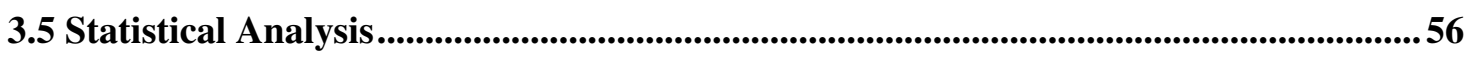



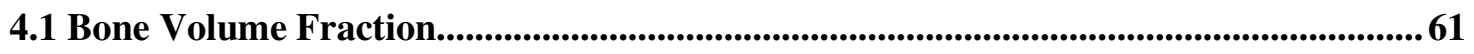

4.2 Activation Frequency ..............................................................................................................62

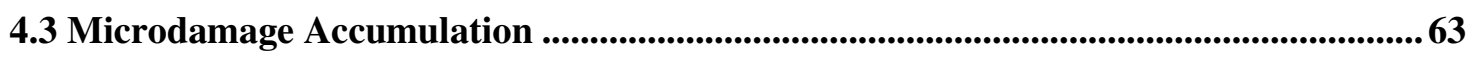

4.4 Limitations and Future Model Considerations.............................................................65

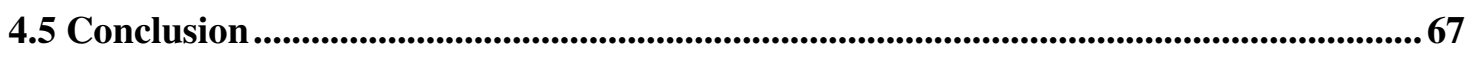



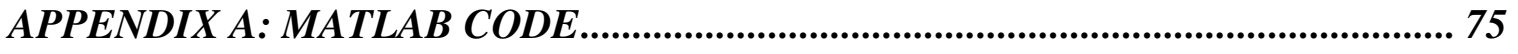

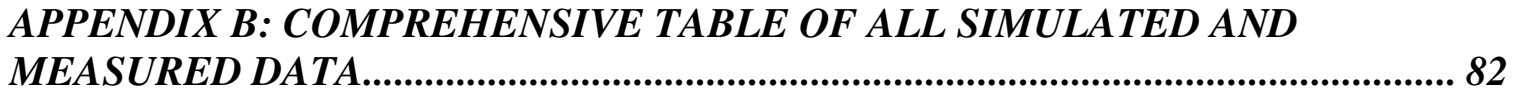




\section{LIST OF TABLES}

Table 1. Basic chemical structure of bisphosphonates. All nBPs have a hydroxyl R1 side

chain and differ only at the $R 2$ side chain

Table 2. Histomorphometric data from 1 year canine rib studies obtained from the

Indiana University School of Medicine.

Table 3. Histomorphometric data from 3 year canine rib studies obtained from the Indiana University School of Medicine.

Table 4. Pre-simulation constants for bone remodeling in cortical bone prior to bisphosphonate treatment

Table 5. Measured 3 year data by treatment for bone volume fraction $(B V / T V)$............ 49

Table 6. Mean $\pm S D$ for the measured 3 year data.

Table 7. Model simulation and experimental measurements for bone volume fraction of the canine rib bone after 1 and 3 years by treatment.... 50

Table 8. Model simulation and experimental measurements for activation frequency of the canine rib bone after 1 and 3 years of ALN treatment.

Table 9. Model simulation and experimental microdamage measurements in the canine rib bone after 1 year and 3 years of ALN treatment.....

Table 10. 1 year ANOVA results for measured activation frequency and damage by treatment

Table 11. 3 year ANOVA results for measured bone volume fraction, activation frequency, and damage by treatment.

Table 12. P-values for individual Tukey comparison for activation frequency for 3 years

of treatment. 57

Table 13. P-values for Ac.f comparing 1 and 3 year experimental values..................... 57

Table 14. P-values for damage comparing 1 and 3 year experimental values................ 58

Table 15. P-values for $t$-test for bone volume fraction for 1 and 3 years by treatment.... 58

Table 16. P-values for t-test for activation frequency for 1 and 3 years by treatment.... 59

Table 17. P-values for t-test for damage for 1 and 3 years by treatment. 60 


\section{LIST OF FIGURES}

Figure 1. Illustration of important features in both cortical and trabecular bone............ 5

Figure 2. Microphotopgraph of cortical bone including important features .................... 6

Figure 3. Microphotograph of normal trabecular bone ............................................... 6

Figure 4. Schematic of bone cells ............................................................................... 8

Figure 5. Histological section of a microcrack found in cortical bone............................ 9

Figure 6. Histological section of a BMU traveling to the right.................................... 12

Figure 7. The comparison between normal and osteoporotic bone .............................. 13

Figure 8. Basic chemical structure of bisphosphonates ............................................ 14

Figure 9. Binding affinity of common bisphosphonates ........................................... 17

Figure 10. Comparison of normal osteoclast function and the effects of $n B P s$ on osteoclasts

Figure 11. Simplified diagram of Carter et al. and Huiskes et al. 's bone adaptability model.

Figure 13. Schematic of the computational model for bone remodeling by Hernandez. et al.

Figure 14. Microdamage accumulation predicted by Nyman et al.. 28

Figure 15. Porous areas in cortical bone under fluorescent microscope. 36

Figure 16. Proposed relationship between the bone volume fraction and the elastic modulus.

Figure 17. Simulation and experimental measurement results for BV/TV for (a) CON and ALNO.2 at 1 and 3 years and (b) CON and ALN1.0 at 1 and 3 years .......................... 51

Figure 18. Simulation and experimental measurement results for activation frequencies for (a) CON and ALNO.2 for 1 and 3 years or treatment and (b) CON and ALN1.0 for 1 and 3 years of treatment

Figure 19. Experiment (mean $\pm S D$ ) and simulation graphs for damage with bisphosphonate treatment starting at $t=0$ (a) ALNO.2, (b) ALN1.0. 


\section{CHAPTER 1: INTRODUCTION}

\subsection{Properties of Bone}

Bone is a dynamic structure whose properties make it ideal for structural support, protection, mineral storage, movement, and cell formation. The properties of bone allow it to adapt to its surrounding environment and optimize its structure in order to maintain its light weight and strength. Bone is a specialized connective tissue made up of an extracellular matrix (ECM) and a cellular component. The ECM is responsible for the functional characteristics of bone tissue like structure and strength and is made up of both organic and inorganic material. The organic material consists mostly of collagen and the inorganic material consists primarily of hydroxyapatite or calcium phosphate crystals. The ECM is the mineralized portion of bone and is maintained by living cells that form the cellular component [1].

\subsection{Bone tissue}

Bone tissue can be classified as either cortical or trabecular bone depending on its porosity (Figure 1). Cortical bone, also referred to as compact bone, forms a very dense cortex around bone with porosities between 5 to 10 percent [2]. The key feature of compact bone is a functional unit called an osteon which is made up of closely packed concentric circular matrices called lamellae. The cylindrical geometry of an osteon makes cortical bone more resistant to fractures because the energy required to form a crack is dissipated along the outer cement line of the circular osteon thus slowing down and even 
stopping crack propagation. This characteristic gives cortical bone a fracture toughness of 2.2-6.3 MPa-m ${ }^{1 / 2}$, elastic modulus of $17.4 \mathrm{GPa}$, and a high tensile ultimate stress of $133 \mathrm{MPa}[1]$. Enclosed in the center of an osteon is the Haversian canal which contains nerves and blood vessels that are essential for providing nutrients and removing wastes from the surrounding cells [2]. Compact bone also consists of Volkman's canals and resorption cavities. The Volkman's canals contain blood vessels that connect the Haversian canals to each other and to the bone surface while the resorption cavities are temporary spaces created by osteoclasts during bone remodeling [2]. The porosity of cortical bone is largely made up of these Haversian canals, Volkmann's canal, and resorption cavities (Figure 2). Trabecular bone, also called cancellous or spongy bone, consists of a network of interconnected struts called trabeculae which are surrounded by bone marrow (Figure 3). In contrast to cortical bone, trabecular bone consists of a more irregular structure, making the bone more fragile with an elastic modulus of $272 \pm 195$ $\mathrm{MPa}$ and an ultimate stress of $2.54 \pm 0.62 \mathrm{MPa}[2]$. Compared to cortical bone, trabecular bone is highly porous and more loosely packed with porosities between 75 to 95 percent [2].

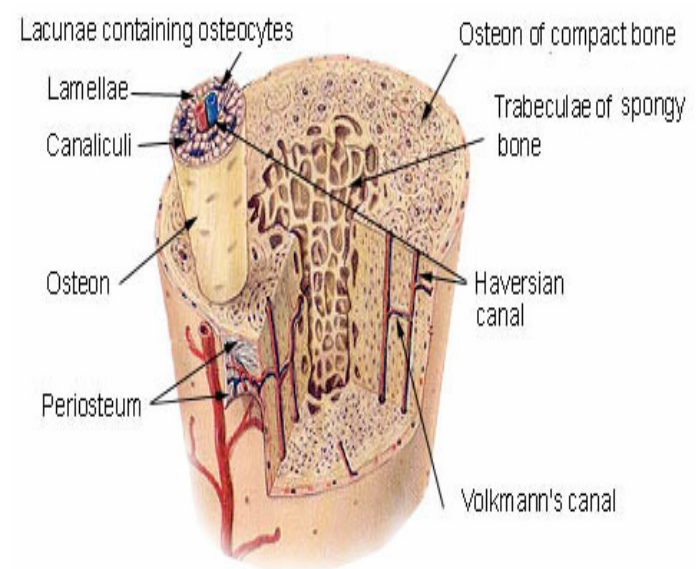

Figure 1. Illustration of important features in both cortical and trabecular bone [3]. 


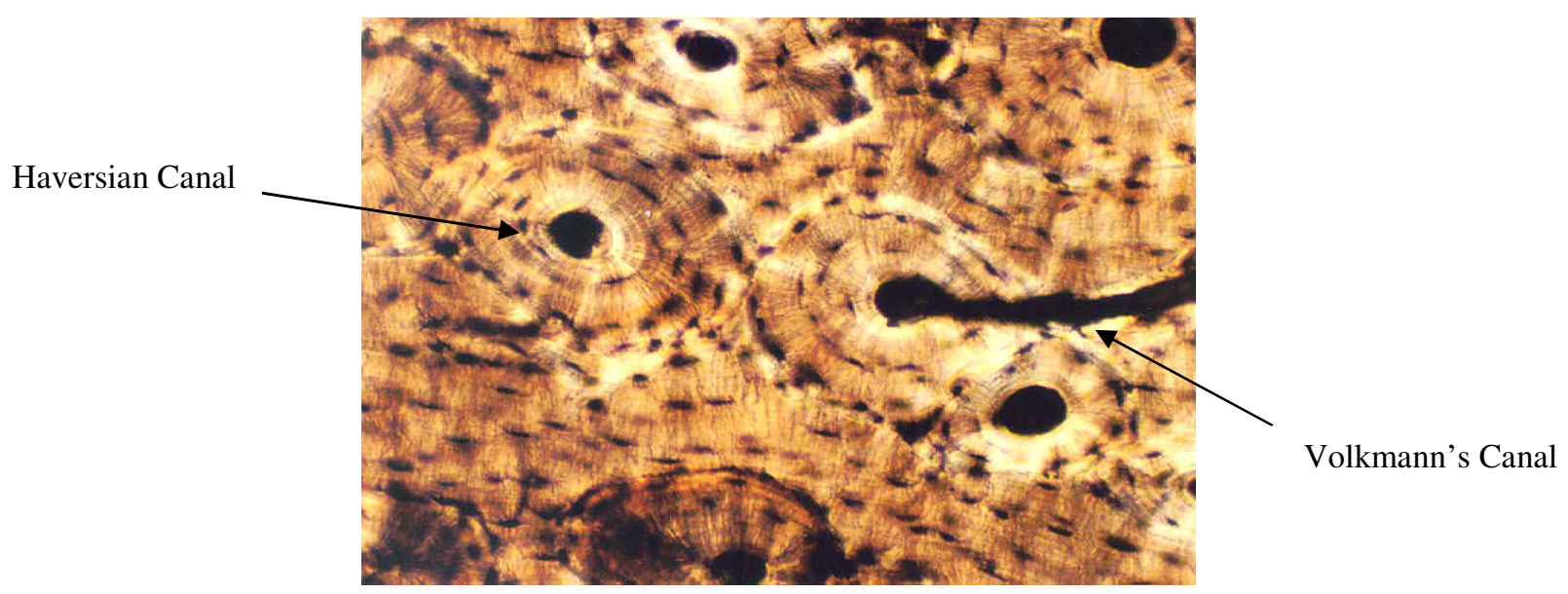

Figure 2. Microphotograph of cortical bone including important features like the osteons, Haversian canals, and Volkmann's canals [46].

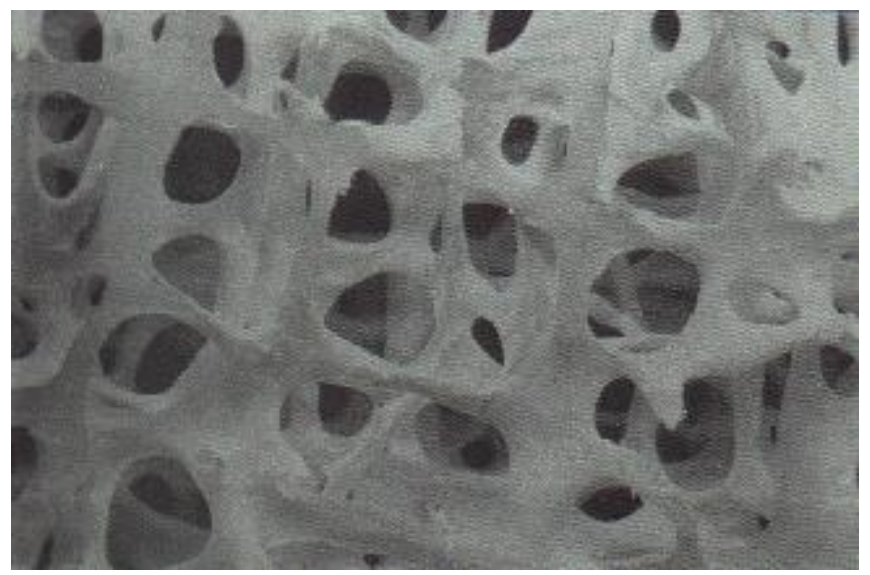

Figure 3. Microphotograph of normal trabecular bone [47].

\subsection{Bone Cells}

The formation of the ECM is due to a collection of bone cells that maintain the matrix. As bone tissue is constantly being loaded, bone cells must work together to remove any fatigue damage caused by stress in order to maintain the integrity of the bone [2]. The cellular component of bone consists of four main cells which can be categorized into two cell types: bone resorbing and bone forming. Cells that resorb bone are similar 
to macrophages whose main role is to phagocytose or remove debris. Cells that form bone are like fibroblasts, whose role is to synthesize and maintain the bone matrix. The four bone cells are osteoclasts, osteocytes, osteoblasts, and bone lining cells (Figure 4).

Osteoclasts are multinucleated cells made in the bone marrow and are responsible for bone resorption. The area of contact between the osteoclasts and the bone matrix forms a ruffled or brushed border where resorption occurs. Hydrogen ions and enzymes are released along this border to demineralize and dissolve the proteins in the matrix [1].

Osteoblasts are bone forming cells found on the border of developing bone. They are mononucleated cells made in the bone marrow and are thought to be activated by mechanical stress [2]. These cells produce an unmineralized matrix called osteoid which is made primarily of type 1 collagen. The apposition rate or the rate at which the osteoid is laid down is about 1 micrometer/day [2]. As the amount of osteoid increases, the osteoblasts get pushed into the developing matrix and become osteocytes.

Osteocytes are mature osteoblasts located within the bone matrix and are thought to play a role in bone turnover by sensing mechanical stress [2]. These cells are embedded in cavities called lacunae and can communicate with other osteocytes and osteoblasts through canals called canaliculi [1]. The canaliculi form tight gap junctions within the bone in which nutrients and chemical signals are passed [2]. This network of communication allows the osteocytes to transmit information and play an important role in bone remodeling.

After osteoblasts have completed filling in a cavity, the cells flatten out and "retire", becoming bone lining cells [2]. Bone lining cells, like osteocytes, are made from osteoblasts; however, unlike osteocytes, these cells do not get buried into the bone matrix 
but rather, become dormant and flatten out discontinuously against the bone surface.

Bone lining cells communicate with osteocytes through gap junctions and are thought to regulate the movement of minerals like calcium and phosphate into and out of the bone.

These cells are also believed to be able to sense changes in mechanical stress and chemical stimuli in order to activate the remodeling process [2].



Figure 4. Schematic of bone cells. The osteoclasts are characterized as being multinucleated and having a ruffled border along the area of contact with the bone. Osteoblasts form bone by producing an unmineralized bone tissue called osteoid which will later become calcified bone matrix. Both osteocytes and bone lining cells are derived from osteoblasts and are either embedded into the matrix (osteocytes) or flattened over the bone surface (bone lining cells) and play a role in the remodeling process [3].

\subsection{Bone Modeling and Remodeling}

Wolff's law states that bone is a dynamic structure that is able to sense mechanical loads and adapt its structure to match the surrounding environment [2]. Bone adaptation is accomplished by two processes called modeling and remodeling.

Bone modeling is the process where bone resorption and bone formation work independently to "customize" the shape of bones [2]. Modeling occurs during childhood allowing bones to sculpt themselves by removing or adding bone to form the optimal 
geometry that will support loads placed on the bone [2]. Bone modeling decreases once the skeleton has matured while remodeling continues throughout an individual's lifetime.

Bone remodeling is the process where bone resorption and bone formation cells work together to form a cellular unit called a basic multicellular unit (BMU) to remove old bone and replace it with newly formed bone [2]. Unlike modeling, remodeling typically does not affect the shape or size of the bone, but instead repairs fatigue damage before it leads to fracture [2]. Because remodeling occurs throughout an individual's lifetime, bone remodeling greatly affects the mechanical properties of bone.

Bone remodeling can be initiated by a number of factors including mechanical stimulus, damage, and chemical factors such as hormone and calcium levels [2]. Bone is designed to maintain homeostasis; so, when strain levels fall below normal, bone is in a state of disuse and bone remodeling is activated in order for BMUs to remove unneeded bone. Similarly, in an overload state, or when there is an increase in loading, remodeling is activated to deposit more bone to maintain the integrity of the bone. Remodeling can also be initiated by cyclic loading which can cause fatigue damage in the form of microcracks that may eventually lead to bone fractures (Figure 5).



Figure 5. Histological section of a microcrack found in cortical bone. Microdamage accumulation can be initiated by cyclic loading which may lead to fractures if not repaired by bone remodeling [48]. 
If the damage is allowed to accumulate, bone strength is compromised and fracture risk is increased; so, bone remodeling is crucial in order to remove damage and prevent bone failure. Bone lining cells have also been thought to trigger remodeling by sensing increases in stress and strain and relaying that information to osteocytes. The osteocytes then recruit osteoclasts to resorb bone at that specific location [2]. Osteocytes can also initiate remodeling by releasing chemical signals that activate remodeling after undergoing apoptosis when sensing changes in stress [2]. The process of bone remodeling can be divided into six stages (Figure 6):

Activation Stage. The first stage is called the activation stage and is initiated by a chemical or mechanical stimulus that triggers progenitor cells to differentiate into osteoclasts [2]. The osteoclasts are then recruited to a specific area to form the resorption area of the BMU.

Resorption Stage. Once the osteoclasts are formed, the cells resorb bone by secreting enzymes and hydrogen ions into the resorption space. Resorption occurs at a rate of about $40 \mu \mathrm{m}$ a day for about 3 weeks in humans [2]. Bone is resorbed in the form of a ditch in trabecular bone and as resorption cavities or a tunnel in cortical bone [2]. Reversal Stage. The reversal stage is where the transition between osteoclasts and osteoblasts take place. Once the osteoclasts have created a cavity for bone formation, the cells undergo apoptosis while the osteoblasts form along the borders of the resorption cavities. The reversal line is often called the cement line because it separates where bone formation begins and marks the boundary of the newly forming osteons from the older bone [2]. 
Formation Stage. Bone formation occurs in two stages: matrix formation followed by mineralization. Osteoblasts deposit an osteoid layer along the outer edge of the resorption cavity. A canal is left in the center of the refilled cavity for the Haversian canal. This is essential to provide the osteoblasts and osteoclasts with nutrients and waste removal. The blood supply also transports calcium and phosphate ions into the bone matrix to nourish the osteocytes [2]. Bone formation takes much longer than resorption, lasting about 3 months.

Mineralization Stage. The second phase of formation is the mineralization stage. During this stage, the unmineralized osteoid tissue becomes mineralized with hydroxyapetite [2]. The mineralization stage happens in two parts: primary mineralization occurs within a couple days and mineralizes about $60 \%$ of the osteoid [2], and secondary mineralization can last up to one year to mineralize the remainder of the osteiod tissue [16]. This delay in mineralization can cause osteons to exhibit different mechanical properties [2]. Quiescence Stage. The final stage of bone remodeling occurs after resorption and formation have completed. The BMUs begin to split apart, prompting osteoclasts to disappear and osteoblasts to become osteocytes, bone lining cells, or disappear entirely [2]. 

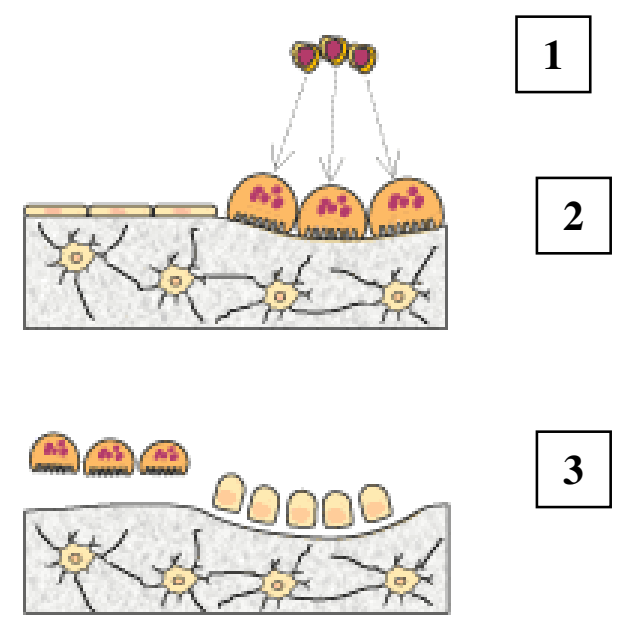

\section{3}
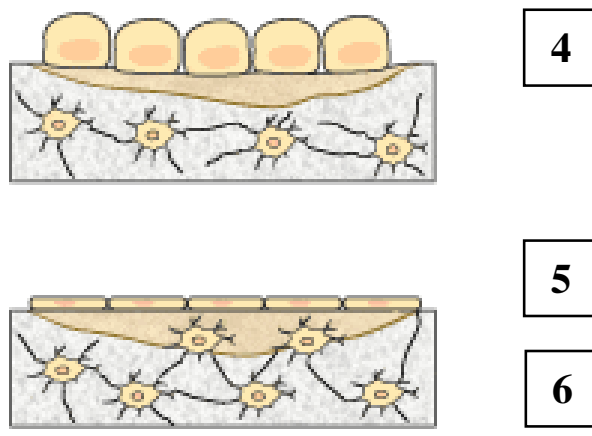

5

6

Figure 6. Bone remodeling stages. (1)Activation is initiated by some stimulus which recruits osteoclasts. (2) Osteoclasts resorb old bone in the resorption stage. (3)The reversal stage is a transition period where resorption ends and formation begins. (4)Osteoblasts form new bone matrix in the formation stage. (5) Osteiod tissue becomes mineralized. (6) Bone formation and resorption are complete and osteoblasts become bone lining cells. [3]

\subsection{Osteoporosis}

Osteoporosis is a common skeletal disorder that is characterized by an imbalance in bone remodeling in which the rate of bone resorption exceeds the rate of bone formation. When more bone is being removed than is being replaced, there is an increase in bone porosity and a loss of bone mass leading to bone fragility and an increase in fracture risk (Figure 7). Some of the common causes of osteoporosis are: immobility, 
malnutrition, age, and a decrease in estrogen which is associated with an increase in osteoclast activity [1]. Individuals who do not exercise and are inactive can increase their chances of developing osteoporosis because bone disuse can lead to bone loss. Lack of nutrients such as calcium and vitamins can also affect the health of bone because they are essential to form the bone matrix [1]. The risk of osteoporosis is further increased with age for both men and women; however, post menopausal women are two and half times more likely to develop signs of osteoporosis as a result of the decrease in estrogen [5].
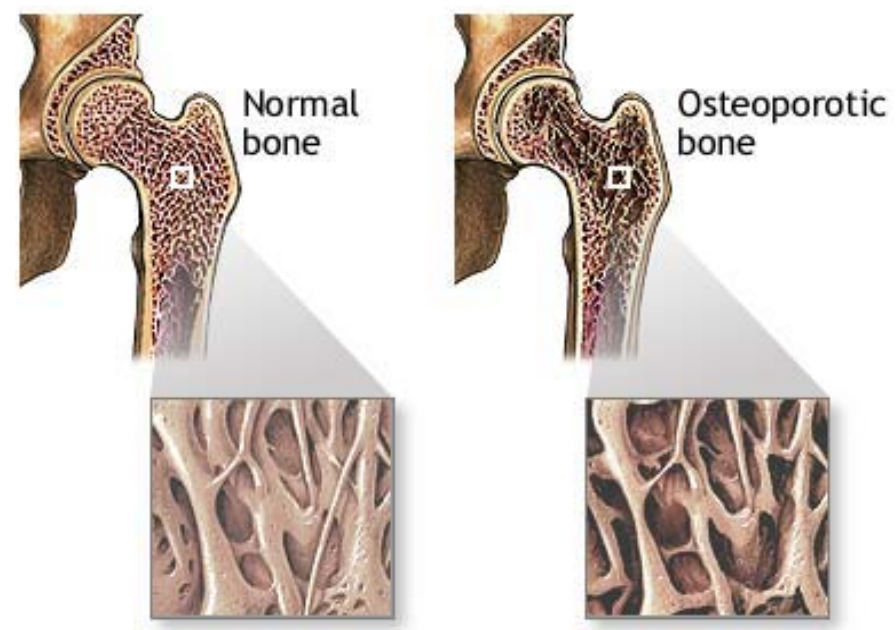

Figure 7. The comparison between normal and osteoporotic bone demonstrates an increase in porosity in the diseased bone as well as a thinning of the bone tissue [6].

The National Osteoporosis Foundation has estimated that the number of people with or at risk for osteoporosis will exceed 52 million by the year 2010 [7]. Because osteoporosis can greatly affect the individual's quality of life, prevention and management of the disease is important. Treatments for osteoporosis hope to reduce bone loss and increase bone formation. Daily doses of calcium and vitamin D can prevent bones from becoming weaker and reduce the risk of osteoporosis. Regular 
exercise can also stimulate bone remodeling and help build stronger bones by reducing bone loss and increasing bone mass. Drug treatments are another effective way to treat and prevent osteoporosis.

\subsection{Bisphosphonates}

Antiresorptive drugs reduce bone remodeling in hopes of increasing bone mineralization and produce a more stable structure [8]. Bisphosphonates are a class of antiresorptive drugs that increase bone mass and reduce fracture risk by suppressing osteoclastic activity by inhibiting the activation of BMUs [33, 35, 36, 37] and reducing the size of bone resorption sites [33, 38, 39, 42]. All bisphosphonates share a common backbone structure composed of two phosphate groups bound by a carbon (Figure 8) [11]. The phosphate groups are negatively charged, giving bisphosphonates a strong affinity to calcium and limiting any side effects of the drug on non skeletal tissues [12]. Bisphosphonates also consists of a $\mathrm{R}_{1}$ and $\mathrm{R}_{2}$ side chain each with their own unique structure that determines the effectiveness of the drug. The $\mathrm{R}_{1}$ side group controls the pharmacokinetics or absorption ability of the drug while the $\mathrm{R}_{2}$ side chain determines the mode of action and the strength of the drug [11].

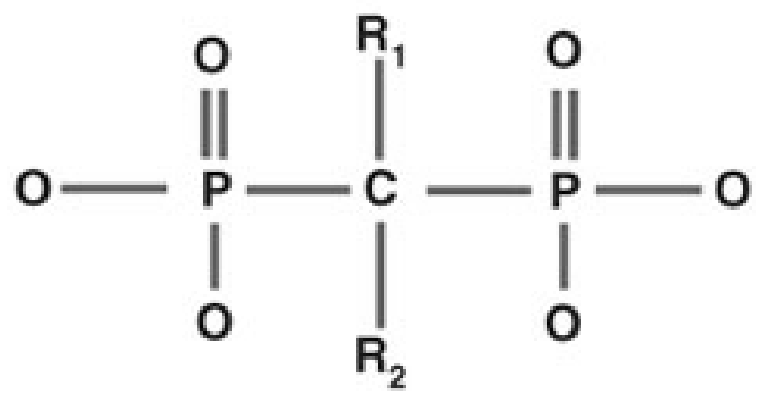

Figure 8. Basic chemical structure of bisphosphonates [13]. 
There are two types of bisphosphonates: nitrogenous and non-nitrogenous bisphosphonates. First generation bisphosphonate do not contain a nitrogen group so are referred to as non-nitrogenous. These drugs are less potent and do not target bone as well as nitrogenous bisphosphonates [12]. Second generation bisphosphonates have a hydroxyl $\mathrm{R}_{1}$ side chain and a nitrogen group on the $\mathrm{R}_{2}$ side chain (Table 1 ). The $\mathrm{R}_{1}$ hydroxyl group enhances the drugs bone binding affinity to hydroxyapatite while the $\mathrm{R}_{2}$ side group determines the anti-resorptive properties of the drug [11]. The different nitrogen based bisphosphonates vary only at the $\mathrm{R}_{2}$ group giving each drug its own pharmacological properties [12].

The structural variations between bisphosphonates explain their differences in binding affinity and anti-resorptive ability [11]. The potency of each bisphosphonate is therefore related to these factors which plays an integral role on the biological effects of the drug. These differences are related to the ability of the drug to attach to bone, its duration of effect, and the ability for the drug to inhibit farnesyl disphosphate synthase (FPP synthase) for nitrogenous based bisphosphonates [11]. This mechanism of action will be explored in more detail in a subsequent section. In vivo and in vitro studies on rats have shown a steady increase in the potency of bisphosphonates with each succeeding generation of drug [11]. More recent bisphosphonates like risedronate, ibandronate, alendronate, and zolendronate were more potent in comparison to older bisphosphonates like etidronate (Figure 9) [11]. The results of the study align with the fact that recent bisphosphonates contain a nitrogen group on their R2 side chain which inhibits FPP and attributes to a higher potency factor [11]. Although nitrogenous bisphosphonates (nBPs) have a higher potency factor, certain nBPs like risedronate do 
not have as strong a binding affinity to bone as others [11]; therefore, the type of bisphosphonate administered and the dosing schedule is important when determining how well the drug will be diffused in the bone and its resorption ability [11]. The effects of bisphosphonates on bone also differ in their ability to reduce bone remodeling, decrease fracture risk, and increase mineralization depending on the drugs structure, potency, treatment dose, length of treatment, and the bone's initial remodeling rate [40]. Higher doses of bisphosphonate can produce increased reductions in activation frequency of up to $93 \%$ [33]; however, this can also result in significantly higher levels of microdamage. Therefore, determining an optimal dosage and potency for different sites are important when treating patients.

Table 1. Basic chemical structure of bisphosphonates. All nBPs have a hydroxyl R1 side chain and differ only at the $\mathrm{R} 2$ side chain [14].

\begin{tabular}{lll} 
Bisphosphonate & $\mathrm{R}_{1}$ Side Chain & $\mathrm{R}_{2}$ Side Chain \\
\hline Alendronate & $-\mathrm{OH}$ & $-\left(\mathrm{CH}_{2}\right)_{3}-\mathrm{NH}_{2}$ \\
Etidronate & $-\mathrm{OH}$ & $-\mathrm{CH}_{3}$ \\
Ibandronate & $-\mathrm{OH}$ & $-\left(\mathrm{CH}_{2}\right)_{2}-\mathrm{N}-\left(\mathrm{CH}_{3}\right)$ (pentyl) \\
Pamidronate & $-\mathrm{OH}$ & $-\left(\mathrm{CH}_{2}\right)_{2}-\mathrm{NH}_{2}$ \\
Risedronate & $-\mathrm{OH}$ & $-\mathrm{CH}_{2}-3-\mathrm{pyridine}$ \\
Zoledronate & $-\mathrm{OH}$ & $-\mathrm{CH}_{2}$-imidazole
\end{tabular}




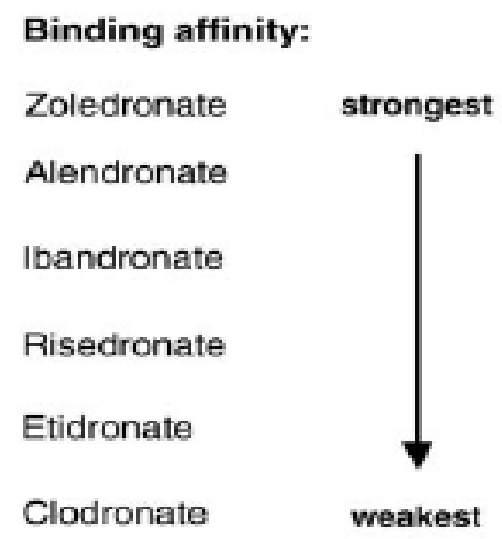

Figure 9. Binding affinity of common bisphosphonates. Zolendronate, Alendronate, Ibandronate, and Risedronate are nBPs and Etidronate and Clodronate are non-nBPs [11].

Alendronate is one of the most commonly prescribed bisphosphonates used for the treatment and prevention of osteoporosis. It was approved for the treatment of osteoporosis by the FDA in 2005 as a second generation nitrogen based bisphosphonate manufactured by Merck \& Co. under the commercial name Fosamax.

Although the exact mechanisms of action for bisphosphonates are not entirely understood, it is clear that bisphosphonates inhibit osteoclasts and reduce bone turnover. The effects of the drug can be categorized into three levels: tissue, cellular, and molecular.

Tissue level. At the tissue level, bone remodeling is reduced due to a suppression in bone resorption [15]. Because resorption and formation are coupled, by decreasing bone turnover rate, the newly formed bone and older bone will have more time to complete mineralization therefore increasing the mineral content of bone [16]. Bisphosphonates increase bone mass by reducing remodeling space which reduces porous areas and creates a positive bone balance where resorption does not exceed formation [10]. 
Cellular level. At a cellular level, bisphosphonates target osteoclasts and areas of bone resorption. Osteoclasts bind to the bone surface as usual, but when bisphosphonates are taken up by the osteoclasts, the cytoskeleton of the cell is disrupted, causing the ruffled border to disappear. Bone resorption declines due to the lack of a ruffled border which plays an integral role in the osteoclasts ability to resorb bone [10].

Molecular Level. At the molecular level, nitrogen based bisphosphonates inhibit farnesyl disphosphate synthase (FPP synthase) which is an enzyme in the mevalonate pathway (Figure 10) [12]. FPP synthase triggers isoprenylation, a process that activates small GTPases such as Rab, Rac, Ras, Rho [12]. GTPase is a family of enzymes that signals proteins that regulate many properties that are important for osteoclast functions involving vesicular trafficking, cytoskeletal arrangement, and membrane ruffling [12]. When the ruffled border of the osteoclast is interrupted, the degradation of the collagen matrix is hindered and the osteoclast's ability to resorb bone is inhibited [12]. High concentration of bisphosphonate can also induce apoptosis and inhibit osteoclast differentiation [12]. 


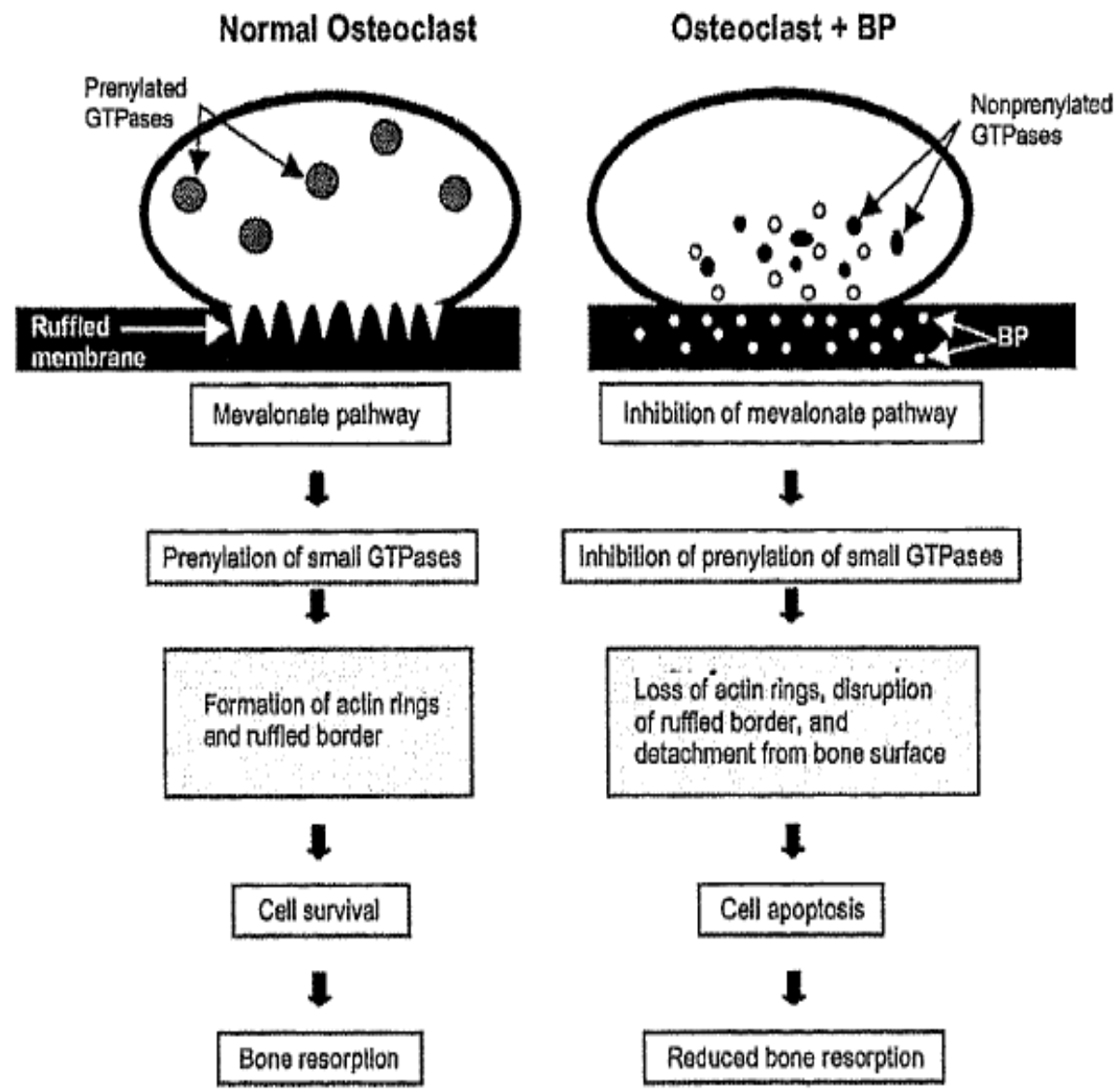

Figure 10. Comparison of normal osteoclast function and the effects of nBPs on osteoclasts [14].

Many experimental studies have been performed that demonstrate the effects of alendronate on bone. Bone strength is one of the determinants of the effects of a bisphosphonate on bone quality. The strength of bone is determined by a number of factors including the bone volume, micro-architecture, and degree of mineralization of bone [43]. Osteoporosis results in bone loss, which causes a weakening of the microarchitecture of bone and an increase in the activation frequency of bone remodeling which effectively reduces the degree of mineralization [43]. In order to offset these harmful effects, alendronate can be given to reduce the bone turnover rate. 
A study by Mashiba et al. [33] showed that the activation frequency for bone remodeling is suppressed after 1 year of alendronate treatment. The decrease in bone remodeling caused microdamage accumulation to increase as well as caused a decrease in the toughness, or the ability to absorb energy, of bone. Histological analysis on the dog ribs also showed a reduction in resorption cavity size with the use of bisphosphonates $[33,36]$.

In addition to reducing activation frequency and reducing resorption cavity area, 1 year bisphosphonate studies have also been found to increase bone mass. The underlying effect of bisphosphonate treatment is to reduce bone resorption which in effect reduces bone formation and reduces the overall bone turnover rate. Within a few month of treatment, a positive bone balance is obtained and primary mineralization is increased [41]. This reduction in bone turnover will then decrease the resorption size and allow for secondary mineralization, both which further increase the bone density and reduce fracture risk [41]. The effects of increasing bone mass should then increase bone strength and improve the mechanical properties of bone [41, 44].

Using alendronate doses equivalent to those used to treat post menopausal osteoporosis, 1 year beagle vertebral studies performed by Allen et al.'s group [17] demonstrated a reduction in the activation frequency of bone remodeling, an increase in microdamage, stiffness, bone volume, and mineralization with no significant effect on the mechanical properties of bone [17]. 3 year rib studies, also performed by Allen et al.'s group [18], showed similar results to 1 year studies; but, this study showed that damage accumulation was not significantly higher compared to the 1 year studies [18]. 
Two and three year studies have also been performed to confirm a reduction in activation frequency and an increase in bone mineral density [36, 42, 43] when alendronate was administered. These results are most likely caused by the increase in mineralization $[36,43]$. The results also show a reduction in fracture rate which has been linked to improved bone strength $[36,43]$. Although many experiments have been performed that demonstrate the effects of alendronate on bone, the short time frames of these studies necessitates additional research to determine the long term effects of bisphosphonates.

Bisphosphonates are used to manage the rate of bone remodeling in order to reduce the risk of fractures; however, when bone remodeling is reduced, microdamage removal is also reduced, making the bone weaker which in the long run, may increase fracture risk and cause bone to be more brittle [10]. Although bisphosphonates suppress bone remodeling and the resorption of bone in order to increase tissue mineralization and bone volume [17], they have also been associated with the impairment of microdamage removal in canines which has been shown to lead to weaker bones [10]. An increase in mineralization along with the increase in microdamage make bone less resistant to crack propagation and more susceptible to fractures [10]. Although several studies have confirmed the increase in microdamage accumulation following bisphosphonate treatment $[9,10,17,18]$, three year results have shown similar levels of microdamage as one year treatment results which suggests that microdamage accumulation is limited beyond the initial increase after one year of treatment [18].

It is important to determine the relationship between bone remodeling and microdamage accumulation in order to understand the long term effects of 
bisphosphonates. The lasting effects of bisphosphonates are still unclear due to the difficulty in obtaining long term data; therefore, developing mathematical models based on the results and relationships from short term studies can be a useful method in predicting the effects of the drug. The purpose of this study is to simulate the effects of alendronate on dog ribs using a computational model based on experimental data results. The mathematical model was developed by simulating results obtained from experimental control data, and then the effects of alendronate treatment on cortical bone remodeling and microdamage in canine ribs were examined by modifying the simulation in an attempt to match one and three year experimental data.

\subsection{Previous Models}

Understanding the variables related to bone remodeling will help to develop a model that can determine the long term effects of alendronate on the mechanical properties of bone. Because bone is a dynamic structure, bone remodeling algorithms must incorporate the effects of bone adaptation to both mechanical and biological stimuli which can be triggered by mechanical loading and fatigue microdamage [19]. Computational models have previously been developed to test hypotheses about bone's adaptability to both biological and mechanical stimuli. Carter et al. [20] and Huiskes et al. [21] introduced the first finite element models to simulate the mechanical adaptability of bone (Figure 11). Both approaches are equivalent but used different coefficients for the daily mechanical stimulus [2]. In these models a daily mechanical stimulus based on stress [20] or strain [21] was used alongside an error function that tracked the change in daily mechanical stimulus in order to calculate changes in the elastic modulus over time. 
The error function is defined as the difference between the actual stress or strain stimulus and the attractor state stimulus or the equilibrium value and is the "driving force for bone remodeling" [45]. The new modulus was obtained by multiplying the changes in the apparent density of the bone by a constant which would be used to calculate the new daily mechanical stimulus for the next time step [2]. This process was repeated in an iterative fashion for the desired period of time. Although both models were able to simulate the mechanical adaptability of bone, neither included a cellular response.

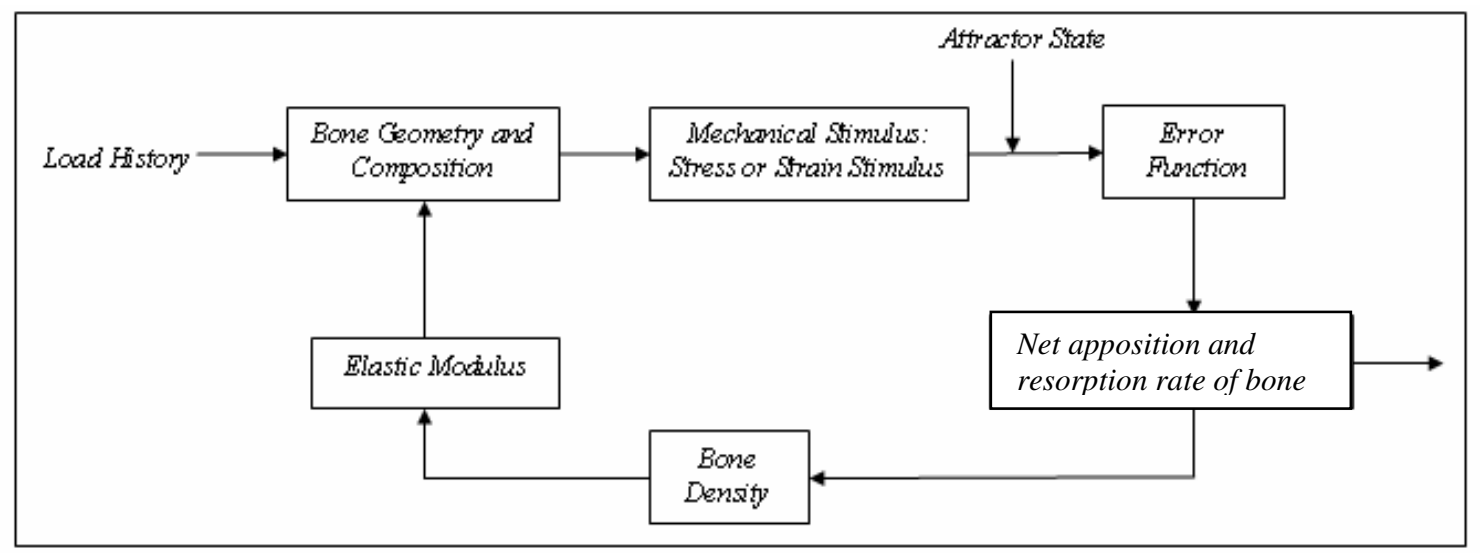

Figure 11. Simplified diagram of Carter et al. and Huiskes et al.'s bone adaptability model.

Hazelwood et al. [19] extended these models to include a more complete representation of bone remodeling by incorporating bone adaptability in response to mechanical and biological stimuli during a state of disuse (low strain) and overload (high strain). Because bone remodeling is activated during both a state of disuse and in a state of overload, porosity and elastic modulus were modified for each time step in order to account for the change in loading (Figure 12). In the model, varying loads were placed 
on a representative bone volume to simulate different loading conditions that would mimic the bone under disuse and overload which was determined by the strain [19]. During disuse (low strain), activation frequency increases, causing the bone porosity to increase due to an elevated resorption cavity area [19]. The elastic modulus is determined using a nonlinear relationship with porosity which is changed for each time step in the model [19]. During overload (high strain), bone is subject to increased damage formation due to the high loading rate. The damage removal rate has previously been modeled by Martin [22]. Similar to the pathway for disuse, the increase in damage triggers an increase in activation frequency which in effect adjusts the porosity of the bone with each time step of the model.

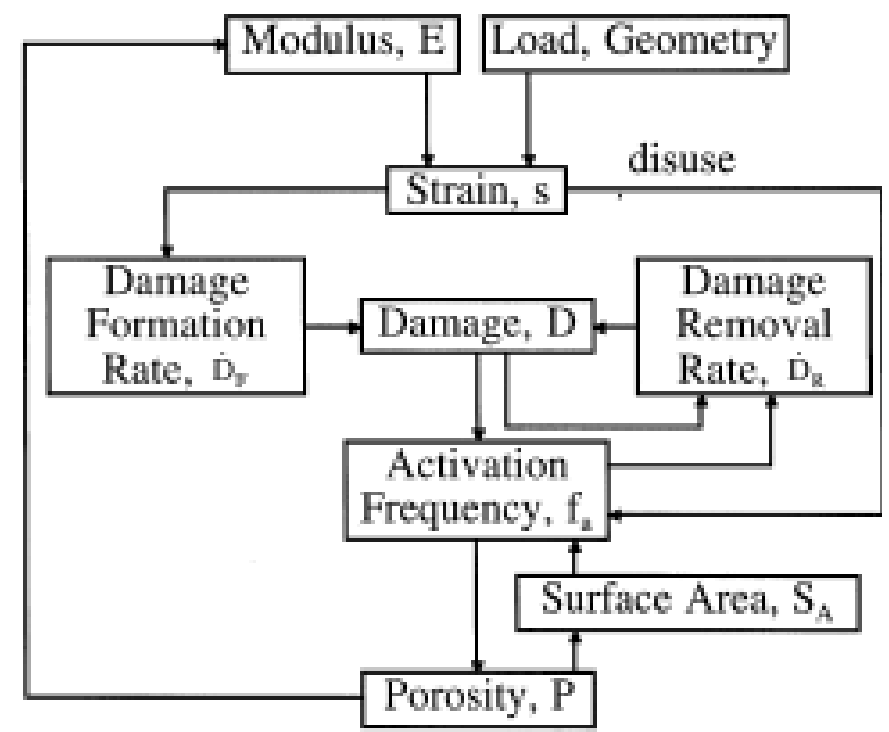

Figure 12. Schematic of bone remodeling algorithm by Hazelwood et al.[19].

In order to simulate the effects of bisphosphonate on bone, clinical data was used to match the results for a mathematical model. Bisphosphonate treatment will reduce the 
bone turnover rate and create a positive bone balance which allows bone mass to increase [16]. The decrease in bone turnover will also reduce the remodeling space area and allow bone more time to mineralize which will cause bone mineral density (BMD) to increase [16]. Hernandez et al. [16] developed a model to compare two methods to simulate the effects of alendronate treatment on BMD (Figure 13). The bone balance method was first introduced by Heaney et al. [23] who modeled alendronate treatment as a decrease in bone turnover, an increase in bone balance, and a constant bone mineralization. The mineralization method on the other hand, modeled alendronate as a constant bone balance and a change in both bone turnover and bone mineralization [16]. The results of both methods were able to predict increases in BMD based on clinical studies; however, the bone balance method attributed the majority of the BMD changes to the bone balance while only accounting for a 6 month secondary mineralization period. Because the time period for secondary mineralization can occur for years, the mineralization method, which incorporated a longer secondary mineralization period, was a better indicator of the long term changes in BMD [16]. Although both Heaney and Hernandez's model were able to calculate changes in BMD, both failed to include the effects of a mechanical stimulus on bone's adaptability. 


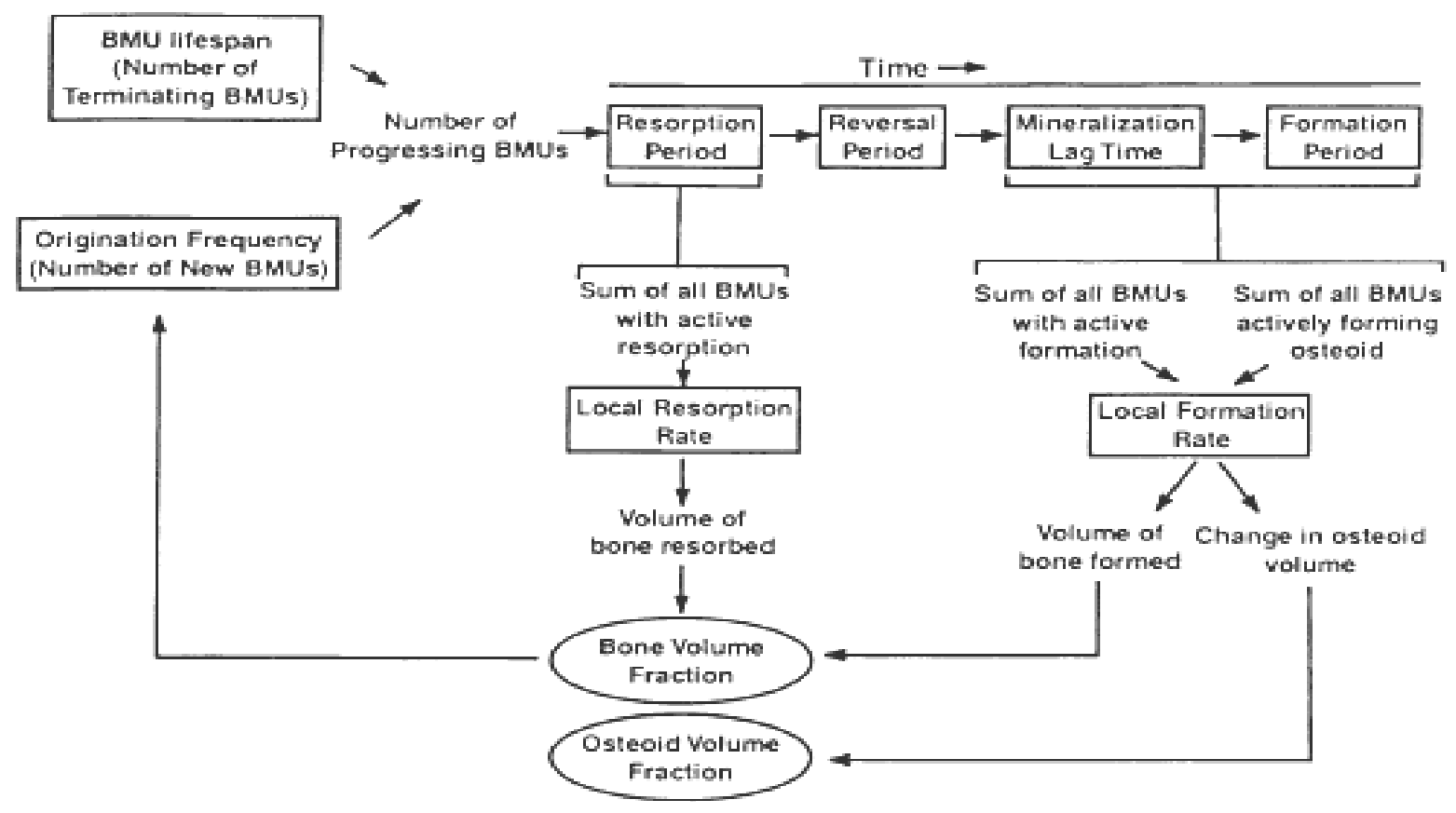

Figure 13. Schematic of the computational model for bone remodeling by Hernandez et al. [16]. The model presents the progression of BMU remodeling activity in a representative volume of trabecular bone over time. The number of active BMUs is dependent on the number of newly formed BMUs and the number of terminating BMUs. As the BMUs advance through the remodeling cycle, they undergo resorption, reversal, mineralization, and a formation period, all which are tracked by the model at each time point. The sum of all BMUs that are resorbing and forming and the resorption and formation rates are then used to calculate the bone volume that is being resorbed or formed at each time step. The volume formed and resorbed is then subtracted to obtain the bone volume fraction which determines the number of new BMUs available for the next time step [16].

By incorporating Hazelwood et al.'s [19] mechanical and cellular responses with the previously described bisphosphonate models, Nyman et al. [10] developed a computational model to simulate the long term effects of bisphosphonate on bone mass and microdamage accumulation in humans by modeling the effects of BMU activation frequency suppression and BMU resorption reduction under a state of disuse, microdamage, and estrogen deficiency [10]. The computational model was developed for trabecular bone remodeling to examine the conditions in which bone mass would increase 
without causing microdamage to linearly increase over time. The results of the model predicted an increase in bone volume with limited microdamage accumulation as long as activation frequency was not completely suppressed [10]. The results were simulated by varying both the potency of the drug and the bone balance in order to determine the optimal amount of activation frequency suppression needed to increase bone volume. The model predicted that microdamage accumulation was limited when activation frequency was incompletely suppressed (Figure 14). In previous models that did not include a disuse response, activation frequency suppression caused an increase in microdamage and resulted in an unlimited bone gain due to the decrease in damage removal and resorption area size respectively [10]. However, by including the disuse response to this model, the increase in bone volume will in effect lower the strain which triggers an increase in activation frequency due to the disuse response and decrease damage formation [10]. The results of the model show that microdamage does not continue to accumulate and the increase in bone mass will plateau over time [10]. Nyman et al.'s [10] model for humans is used as the foundation of the computational model developed here for canine dog ribs, and is more closely examined in the following chapter. 


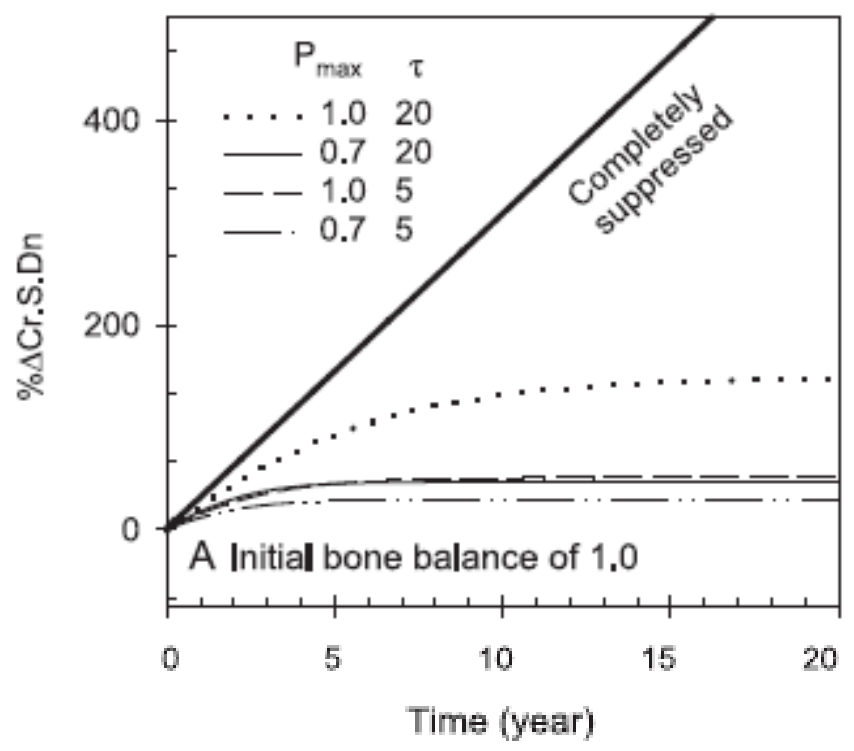

Figure 14. Microdamage accumulation predicted by Nyman et al. [10]. Microdamage was expected to increase linearly over time when the activation frequency was completely suppressed; however, if remodeling was incompletely suppressed, microdamage accumulation was found to increase initially then reach a new equilibrium over time [10].

\subsection{Study Goals}

The objective of this study is to develop a computational model that can simulate the effects of alendronate treatment on canine rib remodeling and microdamage that have been observed in experiments. Although several studies have confirmed an initial increase in microdamage accumulation following bisphosphonate treatment, 3 year treatment results have shown similar levels of microdamage as 1 year treatment results which suggests that microdamage accumulation is limited beyond the initial increase at 1 year of treatment [18]. The long term effects of bisphosphonates are still unclear due to the difficultly in obtaining long term data; therefore, developing a mathematical model 
based on experimental data and relationships from short term studies can be a useful method in predicting the effects of the drug.

The purpose of this study is to modify previous mathematical models to match the control, 1, and 3 year experimental data results from canine studies. The experimental data were obtained from the Indiana University School of Medicine where the dogs were treated with a vehicle or one of two dosages of alendronate. After 1 and 3 years, the dog ribs were excised for analysis and quantified using standard histomorphometric techniques. The mathematical model was developed by simulating results obtained from the experimental control data, and then the effects of alendronate on cortical bone remodeling and microdamage in canine ribs were examined by modifying the simulation in an attempt to match the 1 and 3 year experimental data. Nyman et al.'s computational model for trabecular bone adaptation based on microdamage and mechanical loading [10] was modified in this study to simulate remodeling and bisphosphonate treatment in a representative volume of cortical bone in the canine rib. The model incorporates biological factors and mechanical influences to simulate the remodeling process and is altered in this study to create a program that would match the experimental data for remodeling in the ribs of the 1 year control animals. Using this simulation as the baseline condition, the effects of ALN were modeled by suppressing activation frequency and reducing the resorption area. The changes in BV/TV, damage accumulation, and Ac.f were then simulated for 1 and 3 years and compared to experimental results. Unlike Nyman et al.'s model which involved numerous of assumptions as to which remodeling parameters would be used for human trabecular bone, the present model uses experimental data for cortical canine rib bone to simulate and validate the model. 
This simulation will help in developing improved methods of predicting bisphosphonate treatment on bone as well as determine if the long term effects of bisphosphonate usage will indeed reduce fracture risk. The understanding of the effects of bisphosphonate treatment on dog ribs can also aid in developing better models to simulate the effects of bisphosphonate treatment in humans. 


\section{CHAPTER 2: MATERIALS AND METHODS}

\subsection{Experimental Design}

Before developing the model, histomorphometric data was obtained from experimental results and samples given by the Indiana University School of Medicine in order to validate the results obtained from the model. All experimental procedures were approved by the Indiana University School of Medicine Animal Care and Use Committee prior to beginning the study.

\subsubsection{One Year Canine Experimental Methods}

For the 1 year animal study, seventy-two skeletally mature female beagles (1-2 years old) obtained from Marshall Farms (North Rose, NY) were treated daily for 1 year with oral doses of vehicle (saline control, $1 \mathrm{ml} / \mathrm{kg} /$ day), risendronate sodium (RIS, 0.05 , 0.10, $0.50 \mathrm{mg} / \mathrm{kg} / \mathrm{day}$; Proctor \& Gamble Pharmaceuticals, Norwich, NY), alendronate (ALN, $0.10,0.20$, or $1.00 \mathrm{mg} / \mathrm{kg} /$ day; Merck, RAHWAY, NJ), or raloxifene $(0.50$ mg/kg/day; Lilly Research Labs, Indianapolis, IN) [30]. The middle treatment doses (RIS0.10 and ALN0.20) were determined based on clinically relevant doses used to treat postmenopausal osteoporosis, the higher treatment doses (RIS0.5, ALN1.0) corresponds to $5 \mathrm{x}$ the clinical dose used to treat osteoporosis, and the lower doses (RIS0.05, ALN0.10, raloxifene 0.50) corresponds to approximately half these clinical treatment doses [30]. The recommended dose of alendronate for the treatment of osteoporosis is a $70 \mathrm{mg}$ tablet per week [49] which equals $0.2 \mathrm{mg} / \mathrm{kg} /$ day in a $50 \mathrm{~kg}$ human. Although 
several drugs were compared, for the purpose of the current study, alendronate at 0.2 and $1.0 \mathrm{mg} / \mathrm{kg} /$ day will be the only drug discussed from hereon since it was the only drug used in the 3 year study. Prior to treatment, x-rays of all dogs were taken to ensure skeletal maturity (closed proximal tibia and lumbar vertebra growth plates) [30]. Following a 2 week acclimatization period, the dogs were divided into groups of 12 based on their body weight [30]. The drug treatments were administered orally with a syringe for the vehicle saline solution and by dissolving alendronate into saline each morning after an overnight fast and two hours before feeding [30]. After 1 year of treatment, the animals were intravenously injected with calcein $(0.20 \mathrm{ml} / \mathrm{kg})$ using a $2-12-2-5$ or $2-5-2-5$ labeling schedule then euthanized by intravenously administrating sodium pentobarbital $(0.22$ $\mathrm{mg} / \mathrm{kg}$ ) [30]. The discrepancy in labeling was due to a scheduling error [30]. After necropsy, the right ninth rib was removed and placed in $10 \%$ neutral buffered formalin for 72 hours and then moved to a $70 \%$ ethanol solution for histological assessments [30].

The bone samples were embedded with methyl methacrylate (MMA; Aldrich, Milwaukee, WI) and cut transversely into sections (80-100 $\mu \mathrm{m})$ using a diamond wire saw (Histosaw; Delaware Diamond Knieves, Wilmington, DE) [30]. One cross sectional bone sample per animal was used for the measurements using a semiautomatic system (Bioquant OSTEO 7.20.10; Bioquant Image Analysis, Nashville, TN) attached to a microscope equipped with an UV light source (Nikon Optiphot 2; Nikon, Tokyo, Japan) [30]. Analysis for the 1 year study was performed by the Indiana University School of Medicine and the results are listed below (Table 2). 
Table 2. Histomorphometric data from 1 year canine rib studies obtained from the Indiana University School of Medicine

\begin{tabular}{|c|c|c|c|c|}
\hline & $\begin{array}{c}\text { Vehicle } \\
(1 \mathrm{ml} / \mathrm{kg} / \text { day })\end{array}$ & $\begin{array}{c}\text { Alendronate } \\
(0.20 \mathrm{mg} / \mathrm{kg} / \text { day })\end{array}$ & $\begin{array}{c}\text { Alendronate } \\
(1.00 \mathrm{mg} / \mathrm{kg} / \mathrm{day})\end{array}$ & Source \\
\hline Formation Period, days & $66.14 \pm 55.12^{*}$ & -- & -- & [30] \\
\hline $\begin{array}{c}\text { Activation Frequency, } \\
\# / \mathbf{m m}^{2} / \text { day }\end{array}$ & $0.0384 \pm 0.0290^{*}$ & $0.0361 \pm 0.0322^{*}$ & $0.0202 \pm 0.0134^{*}$ & [30] \\
\hline $\begin{array}{l}\text { Microdamage } \\
\left(\mathbf{m m} / \mathbf{m m}^{2}\right)\end{array}$ & $0.0169 \pm 0.0189^{*}$ & $0.0326 \pm 0.0339^{*}$ & $0.0332 \pm 0.0393^{*}$ & [30] \\
\hline
\end{tabular}

"Unpublished data from specimens in [30].

\subsubsection{Three Year Canine Experimental Methods}

For the 3 year study, Indiana University School of Medicine performed a canine study on thirty-six skeletally mature female beagles (1-2 years old, $n=36)$ [24]. X-rays of the dogs were acquired to confirm skeletal maturity (closed proximal tibia and lumbar vertebra growth plates) [24]. Following a 2 week acclimatization period, the animals were divided into 3 groups $(n=12$ /group) each treated daily for 3 years with oral doses of vehicle (saline control, $1 \mathrm{ml} / \mathrm{kg} / \mathrm{day}$ ) or alendronate (ALN, 0.2 or $1.00 \mathrm{mg} / \mathrm{kg} / \mathrm{day}$; Merck and Co.) [24]. The dosing for the alendronate treatment corresponds to doses used to treat postmenopausal osteoporosis (ALN0.2) and 5 times that amount used to treat Paget's disease (ALN1.0) [24]. The drug treatments were administered orally with a syringe for the vehicle saline solution and by dissolving alendronate into saline each morning after an overnight fast and two hours before feeding [24]. All 36 animals completed the 3-year study with no serious complications [24]. Following 3 years of treatment, the animals were injected with calcien $(5 \mathrm{mg} / \mathrm{kg}$ as a $3 \%$ solution, IV) on a 2- 
12-2-5 labeling schedule prior to necropsy [24]. The animals were euthanized by intravenous administration of sodium pentobarbital $(0.22 \mathrm{mg} / \mathrm{kg}$ Beuthanasia-D Special $)$ and the mid section of the ninth rib was removed and preserved in $70 \%$ ethanol or $10 \%$ neutral buffered formalin for microdamage and histomorphometric evaluation, respectively [18]. In addition, the left eleventh rib was maintained in a saline soaked gauze and frozen to $-20^{\circ} \mathrm{C}$ for further measurements [18]. From these experiments, the following results were obtained from the Indiana University School of Medicine and used for the model (Table 3).

Table 3. Histomorphometric data from 3 year canine rib studies obtained from the Indiana University School of Medicine

\begin{tabular}{|c|c|c|c|c|}
\hline & $\begin{array}{c}\text { Vehicle } \\
(\mathbf{1 m l} / \mathbf{k g} / \mathbf{d a y})\end{array}$ & $\begin{array}{c}\text { Alendronate } \mathbf{( 0 . 2 0} \\
\mathbf{m g} / \mathbf{k g} / \mathbf{d a y})\end{array}$ & $\begin{array}{c}\text { Alendronate 1.00 } \\
\mathbf{m g} / \mathbf{k g} / \mathbf{d a y})\end{array}$ & Source \\
\hline $\begin{array}{c}\text { Activation Frequency, } \\
\text { \#/mm2/day }\end{array}$ & $0.00902 \pm 0.00780^{*}$ & $0.00153 \pm 0.00215^{*}$ & $0.00521 \pm 0.00792^{*}$ & {$[24]$} \\
\hline $\begin{array}{c}\text { Microdamage } \\
(\mathbf{m m} / \mathbf{m m 2})\end{array}$ & $0.0248 \pm 0.0274$ & $0.0449 \pm 0.0273$ & $0.0408 \pm 0.0216$ & {$[24]$} \\
\hline $\begin{array}{c}\text { Elastic Modulus } \\
\text { (MPa) }\end{array}$ & $5601 \pm 318$ & $5524 \pm 320$ & $5678 \pm 407$ & {$[24]$} \\
\hline
\end{tabular}

*Unpublished data from specimens in [24].

\subsection{Sample Preparation}

For the histomorphometric analysis in the previous studies performed at the Indiana University School of Medicine, the bone samples were stained en bloc with $1 \%$ basic fuschin and embedded undecalcified in methyl methacrylate [24]. Thirty-six bone samples from the 3 year canine rib study were obtained from the Indiana University 
School of Medicine and used to obtain further data described below. Using the facilities at Cal Poly, two transverse sections were cut from each of the thirty-six bone samples using a high precision bone saw (Isomet 1000; Buehler Ltd., Lake Bluff, IL), then sanded to a thickness of around 100 micrometers using 400 grit sandpaper and mounted onto microscope slides (Eukitt Mounting Medium; Electron Microscopy Sciences, Hatfield,PA).

\subsection{Histomorphometric Analysis}

For this study, the 1 and 3 year experimental data for activation frequency (Ac.f) and microdamage for the control and both doses of alendronate were obtained from the Indiana University School of Medicine (Table 2 and 3). Since the 3 year bone samples were also provided for analysis at Cal Poly, histomorphometric measurements to determine the bone volume fraction (BV/TV) were performed for the control and both dosages of alendronate to be used as a reference to develop the computer model. All measurements were performed blinded. After preparing the samples for analysis, a semiautomatic analysis system (Bioquant Image Analysis, Nashville, TN) attached to a microscope equipped with an UV light source (Nikon, Tokyo, Japan) was used to calculate the bone volume fraction. For each of the thirty-six bone samples, two transverse sections were cut per bone sample ( 72 total) and used to measure the porous areas of the cortical portion of the bone including the resorption spaces, Volkmann's canals, and Haversian canals (Figure 15). The bone's microstructure was analyzed using Bioquant by manually circling the porous spaces in multiple sections of the entire cortical bone sample. The porous areas for each section were then added together and divided by 
the total cross section of the cortical bone area to obtain the porosity of the bone sample. Because two slides were made per bone sample the porosity value for each slide was averaged to get one value. The BV/TV was then calculated as 1 minus the porosity.

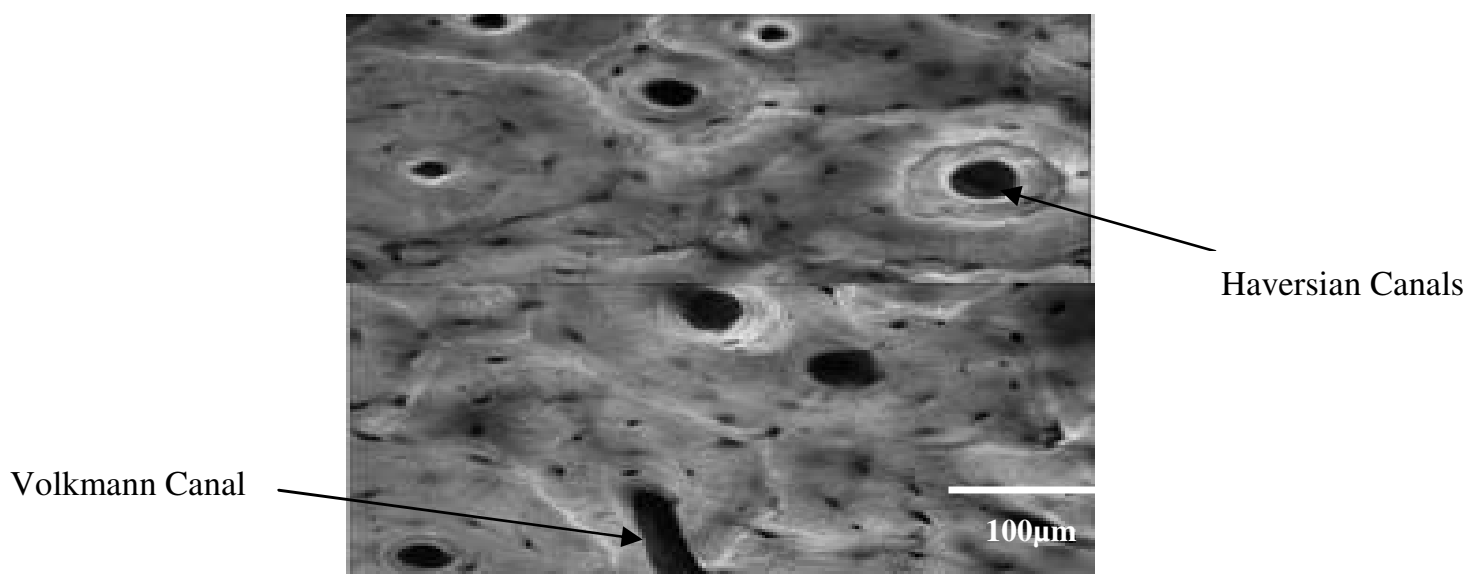

Figure 15. Porous areas in cortical bone under fluorescent microscope.

\subsection{Remodeling Simulation}

Mechanical Loading. The model simulates adaptive remodeling in a $1 \mathrm{~cm}^{3}$ representative volume of cortical rib bone under uniaxial cyclic loading. Assuming a linear relationship between the apparent density $(\rho)$ and the porosity (p), the elastic modulus (E) of the representative volume was assumed to be proportional to the bone volume fraction (BV/TV) in the following relationship,

$$
E=E_{0} \times(B V / T V)^{a}
$$

where $\mathrm{E}_{0}=6634.24, \mathrm{a}=5.4994$, and $\mathrm{BV} / \mathrm{TV}=(1-\mathrm{p})$ for cortical rib bone. These values were estimated given the available data for the elastic modulus (Table 3) and the 
measured values for the bone volume fraction (Table 5) from the 3 year experimental study [24]. The elastic modulus and bone volume fraction values were input into Eq.1 for each treatment group (CON, ALN0.2, ALN1.0) to obtain three equations, and linearized by applying the natural $\log$ to both sides. The general formula used was:

$\ln E=a \ln \left(\frac{B V}{T V}\right)+\ln E_{0}$,

which follows the equation $y=m x+b$, or in this case, $\ln (\mathbf{y})=\mathbf{m} \ln (\mathbf{x})+\ln \mathbf{b}$ where " $\mathrm{m}$ " is the slope and corresponds with the "a" in Eq. 2 and "lnb" is the y-intercept which corresponds to the $\ln \mathrm{E}_{0}$. To find the slope and y-intercept, $\ln (\mathrm{BV} / \mathrm{TV})$ versus $\ln \mathrm{E}$ was plotted out for each treatment group. The slope of the best fit line was adjusted, within range of the standard deviations, to create a positive slope of $a=5.4994$ (Figure 16). The elastic modulus was calculated by taking the e of the $y$-intercept to obtain $\mathrm{E}_{0}=6634.24$.



Figure 16. Proposed relationship between the bone volume fraction and the elastic modulus. 
As described in the previous models, the porosity and elastic modulus adapt throughout the simulation based on the effects of disuse and damage on bone remodeling (Figure 12). Although porosity is used throughout the simulation, the porosity is changed to bone volume fraction $(\mathrm{BV} / \mathrm{TV}=1-$ porosity) for the analysis. The disuse and damage response are modeled using the strain and the loading rate of the representative volume. Using Hooke's Law, the peak strain $(\varepsilon)$ was calculated as

$$
\varepsilon=\sigma / E
$$

and the mechanical stimulus or loading potential was defined as

$$
\Phi=r l 1 \times \varepsilon^{q},
$$

where $\mathrm{rl} 1$ is the loading frequency in cycles per day (cpd) and q is a constant that adjusts the peak strain and loading frequency to the loading potential [10].

Porosity Transformation. The change in porosity is associated with the bone resorbing rate $\left(\mathrm{Q}_{\mathrm{R}}\right)$ and bone refilling rate $\left(\mathrm{Q}_{\mathrm{F}}\right)$ for each $\mathrm{BMU}$, and the number of resorbing $\left(\mathrm{N}_{\mathrm{R}}\right)$ and refilling BMUs $\left(\mathrm{N}_{\mathrm{F}}\right)$ per unit area. The resorption rate,

$$
Q_{R}=A_{R} / T_{R}
$$

and the refilling rate,

$$
Q_{F}=A_{F} / T_{F}
$$


were assumed to be linearly related with time where $A, T_{R}$, and $T_{F}$ are the cross-sectional area of each BMU, the resorption period, and the refilling period, respectively [26,27]. The number of resorbing BMUs $\left(\mathrm{N}_{\mathrm{R}}\right)$ and the number of refilling BMUs $\left(\mathrm{N}_{\mathrm{F}}\right)$ was found by integrating the BMU activation frequency over the present time $(t)$, resorption $\left(T_{R}\right)$, reversal $\left(\mathrm{T}_{\mathrm{V}}\right)$ and refilling $\left(\mathrm{T}_{\mathrm{F}}\right)$ time periods accordingly,

$$
\begin{aligned}
& N_{R}=\int_{t-T_{R}}^{t} A c f\left(t^{\prime}\right) d t^{\prime} \\
& N_{F}=\int_{t-\left(T_{R}+T_{V}+T_{F}\right)}^{t-\left(T_{R}+T_{V}\right)} A c f\left(t^{\prime}\right) d t^{\prime}
\end{aligned}
$$

to obtain the change in porosity:

$$
\dot{p}=Q_{R} N_{R}-Q_{F} N_{F}
$$

$T_{R}$ is the time interval beginning from the instance resorption begins to the moment the osteoclasts stop resorbing. $T_{V}$ is the inactive transition period between osteoclastic to osteoblastic activity, and $\mathrm{T}_{\mathrm{F}}$ is the interval in which osteblasts from the BMU form bone [19].

BMU Activation Frequency. The activation frequency is the number of new BMUs created per unit area per time (BMUs $/ \mathrm{mm}^{2} /$ day). BMU activation frequency was assumed to be a function of both damage and disuse and the specific surface area $\left(\mathrm{S}_{\mathrm{A}}\right)$ in the equation: 


$$
A c f=\left(A c f_{(\text {disuse })}+A c f_{(\text {damage })}\right) S_{A} .
$$

The specific surface area is the amount of surface area available for new BMUs, which is also defined as the bone surface per total sectional area (BS/TA). In order to ensure that the area taken up by the new BMUs did not exceed the available surface area, $\mathrm{S}_{\mathrm{A}}$ was divided by the maximum specific surface area $\left(S_{A \max }\right)$ to obtain values between 0 and 1 in a relationship between porosity and surface area,

$$
\frac{B A}{T S}=S_{A}=\left(32.1 p-93.9 p^{2}+134 p^{3}-101 p^{4}+28.8 p^{5}\right) / S_{A \max },
$$

which was developed by Martin [28]. The activation frequency was then normalized using $\mathrm{S}_{\mathrm{A}}$. The activation frequency for microdamage and disuse was calculated by fitting hypothetical dose response curves for activation in response to disuse and damage [10]. The disuse response was defined as a mechanical stimulus value $\Phi$ below the equilibrium mechanical stimulus value $\Phi_{0}$. During a state of disuse $\left(\Phi<\Phi_{0}\right)$, the refilling rate $\left(\mathrm{Q}_{\mathrm{F}}\right)$ is reduced; so, the area of bone formation was also reduced by adjusting the area of formation by $\mathrm{A}\left[0.5+0.5\left(\Phi / \Phi_{0}\right)\right]$ to account for the reduction in refilling rate on the bone surface [19]. The relationship between the activation frequency and the disuse and damage was modeled assuming a sigmoidal relationship [19] between mechanical stimulus and $\operatorname{Acf}_{\text {(disuse) }}$

$$
A c f_{(\text {disuse })}=\frac{A c f_{(\max )}}{1+e^{k_{b}\left(\Phi-k_{c}\right)}} \quad \text { for } \Phi<\Phi_{0 .}
$$


and damage and $\operatorname{Acf}_{(\text {damage })}$,

$$
A c f_{(\text {damage })}=\frac{\left(A c f_{0}\right)\left(A c f_{(\max )}\right)}{A c f_{0}+\left(A c f_{(\max )}-A c f_{0}\right) e^{\left.\mid k_{r}^{\left(A c f_{(\max )}\right)\left(D-D_{0}\right) / D_{0}}\right]}}
$$

where $\mathrm{D}_{0}$ corresponds to the initial equilibrium damage and $A c f_{(\max )}$ was the maximum allowable activation frequency which was intended to be much higher than the highest average activation frequency for human cortical bone assuming that the value would not reach this upper limit $[19,29]$. The sigmoidal curves were found by matching the responses found in pharmacological applications [19]. The constants $\mathrm{k}$ were determined by fitting the curves based on a range of clinical data [19]. The coefficients $k_{r}(-1.7), k_{b}$ $\left(1.1 \times 10^{15} \mathrm{cpd}^{-1}\right)$, and $\mathrm{k}_{\mathrm{c}}\left(5.739565 \times 10^{-15} \mathrm{cpd}\right)$ influence the shape, slope, and inflection point of the curves respectively [19].

Microdamage Accumulation. Microdamage (D) is defined as the total crack length per section area of bone. According to Martin [22], the rate of fatigue damage accretion is:

$$
\dot{D}=\dot{D}_{F}-\dot{D}_{R}
$$

where $\dot{D}_{F}$ and $\dot{D}_{R}$ are the damage formation and removal rates, respectively and are equal in a state of equilibrium. The rate of damage formation was assumed to be a function of the mechanical stimulus $\Phi$ [22] which was defined as:

$$
\dot{D}_{F}=k_{D} \Phi
$$


where $\mathrm{k}_{\mathrm{D}}$ is the damage coefficient and $\Phi=\varepsilon^{\mathrm{q}} \mathrm{x}$ rl1 is the damage potential as described earlier. For simplicity, the strain and peak strain ( $\varepsilon$ ) are equivalent [19]. Martin's model [22] also assumes that fatigue damage removal is proportional to the amount of damage that exists in the following relationship:

$$
\dot{D}_{R}=D A c f A f_{S},
$$

where Acf is the amount of BMUs found in the representative section per day, A is the area of all completed resorption areas, and $\mathrm{f}_{\mathrm{s}}$ is a damage removal specificity factor. Although damage is randomly distributed in the bone, it has been shown that damage initiates activation frequency [24], which improves the efficiency that damage is removed compared to that of random removal [19]. To account for this, the damage removal specificity factor was included and assumed to be 5 based on experimental results [19, 24]. By assuming there is no net damage accumulation for the baseline conditions, the damage rate coefficient $\left(\mathrm{k}_{\mathrm{D}}\right)$ can be determined by setting $\dot{D}_{F}$ equal to $\dot{D}_{R}$ to obtain the following equation,

$$
k_{D}=D_{0} A c f_{0} A f_{S} / \Phi_{0},
$$

where the initial equilibrium conditions are denoted by the subscript 0 .

Baseline model development. Prior to applying bisphosphonate treatment to the model, equilibrium conditions were set based on the 1 year experimental control data. Utilizing Nyman et al.'s [10] model for human vertebrae bone remodeling, physiological parameters were modified in order to adjust this model for cortical bone in canine ribs. 
Pre-simulation parameters were calculated (Table 4) or estimated using data from experimental results obtained from the Indiana University School of Medicine or past studies. The control values were obtained by running the model until the results reached equilibrium which took about 2000 iterations (or days). As we were unable to obtain bone volume fraction values from 1 year experimental control animals, baseline bone volume fraction was assumed to be similar to 3 year values for cortical rib bone at $\mathrm{BV} / \mathrm{TV}=0.9675$, which was obtained from histomorphometric analysis of 3 year samples. The applied force and equivalent stress on the $100 \mathrm{~mm}^{2}$ cross-section from the $1 \mathrm{~cm}^{3}$ representative bone sample to produce the desired BV/TV was set at $13.465 \mathrm{~N}$ and $.13465 \mathrm{MPa}$ respectively. The resulting BV/TV was 0.9651 , which was within range of the 1 year experimental control data. Both the force and stress were kept constant for the entire bisphosphonate treatment. 
Table 4. Pre-simulation constants for bone remodeling in cortical bone prior to bisphosphonate treatment.

\begin{tabular}{|c|c|c|c|}
\hline Constant (units) & Description & Nominal Value & Source \\
\hline $\mathrm{R}_{\mathrm{c}}(\mathrm{mm})$ & Cement line radius & 0.19828147 & {$[30]$} \\
\hline $\mathrm{R}_{\mathrm{h}}(\mathrm{mm})$ & Haversian canal radius & 0.0551558 & [30] \\
\hline $\mathrm{T}_{\mathrm{r}}$ (days) & Resorption period & 25 & [19] \\
\hline $\mathrm{T}_{\mathrm{v}}$ (days) & Reversal period & 5 & [19] \\
\hline $\mathrm{T}_{\mathrm{f}}$ (days) & Formation period & $66^{*}$ & {$[30]$} \\
\hline $\operatorname{phi}_{0}(\mathrm{cpd})$ & Initial mechanical stimulus & $1.1479 \times 10^{-14 * \dagger}$ & [31] \\
\hline por $_{0}$ & Initial Porosity & $0.0324591^{* \S}$ & {$[24]$} \\
\hline $\mathrm{k}_{\mathrm{b}}\left(\mathrm{cpd}^{-1}\right)$ & $\begin{array}{l}\text { Activation frequency dose-response } \\
\text { coefficient }\end{array}$ & $1.1 \times 10^{15 * \dagger}$ & [19] \\
\hline $\mathrm{k}_{\mathrm{c}}(\mathrm{cpd})$ & $\begin{array}{l}\text { Activation frequency dose-response } \\
\text { coefficient }\end{array}$ & $5.739565 \times 10^{-15^{*}}$ & [19] \\
\hline$f_{s}$ & Damage removal specificity factor & 5 & [19] \\
\hline $\mathrm{d}_{0}\left(\mathrm{~mm} / \mathrm{mm}^{2}\right)$ & Initial Damage & $0.03578^{*}$ & {$[30]$} \\
\hline $\mathrm{k}_{\mathrm{r}}$ & $\begin{array}{l}\text { Activation frequency dose-response } \\
\text { coefficient }\end{array}$ & $-1.7^{* \dagger}$ & [19] \\
\hline rl1 (cpd) & Loading rate & $21600^{* \dagger}$ & [31] \\
\hline $\mathrm{q}$ & Damage rate exponent & 4 & [19] \\
\hline $\mathrm{k}_{\mathrm{d}}\left(\mathrm{mm} / \mathrm{mm}^{2}\right)$ & Damage rate coefficient & 9779300000 & {$[19]$} \\
\hline $\begin{array}{c}\text { Acf }_{0} \\
\text { (BMUs/mm²/day) }\end{array}$ & Initial BMU activation frequency & $0.0051^{*}$ & {$[30]$} \\
\hline $\begin{array}{c}\mathrm{Acf}_{\max } \\
\left(\mathrm{BMUs} / \mathrm{mm}^{2} / \text { day }\right)\end{array}$ & $\begin{array}{c}\text { Maximum BMU activation } \\
\text { frequency }\end{array}$ & 0.5 & [19] \\
\hline $\mathrm{S}_{\mathrm{amax}}$ & $\begin{array}{l}\text { Maximum specific surface area, } \\
\text { normalizing constant }\end{array}$ & 4.1905 & [19] \\
\hline
\end{tabular}

Unpublished data.

$\S$ Measured data.

${ }^{\dagger}$ Estimated data. Constants $\mathrm{k}_{\mathrm{b}}$ and $\mathrm{k}_{\mathrm{r}}$ were determined by fitting sigmoidal curves based on the new cortical dog rib data. rl1 was determined using a respiratory rate of 15 breaths per minute to obtain a loading rate of $21600 \mathrm{cpd}$ and $\mathrm{phi}_{0}$ was estimated from the number of loading cycles (rl1) and the estimated strain. 
Simulation of Bisphosphonate. After developing a baseline model that successfully simulated canine rib bone remodeling based on control experimental data, bisphosphonate treatment was incorporated into the program. Bisphosphonate treatment was modeled for 3 years based on the assumption that the treatment would reduce two factors: activation frequency and BMU resorption area [10]. A potency variable $\mathrm{P}$, where $0 \leq \mathrm{P} \leq 1$, was used to model the effectiveness of bisphosphonates in suppressing remodeling. The potency was derived from pharmacokinetic properties of bisphosphonate including its ability to suppress remodeling activation based on the chemical structure and dosage of the drug, its ability to bind to areas of bone resorption, its ability to be taken up by bone, and its mode of action [10] in the following equation:

$P=P_{\max }\left(1-e^{-\tau_{s} \times N_{R} B M U}\right)$,

where $P_{\max }$ and $\tau_{\mathrm{s}}$ are suppression coefficients that are intended to match the dosage and structure of the bisphosphonate. These values were modified to match within 1 standard deviation, the mean experimental data for 1 and 3 year alendronate treatment of the bone volume fraction, activation frequency, and damage. Although these values are not definitive, higher $\tau$ and $P_{\max }$ values reflect a higher dose of alendronate and lower $\tau$ and $\mathrm{P}_{\max }$ values indicate a lower potency. For the model, different iterations of $\mathrm{P}_{\max }$ values ranging between 0 and 1 and tau values between 1 and 20 were used to obtain the desired results. These ranges were determined based on past studies [10]. P was then multiplied by the activation frequency in the equation,

$$
A c f=(1-P)\left(A c f_{\text {(disuse) }}+A c f_{(\text {damage })}\right) S_{A},
$$


to simulate bisphosphonate's ability to suppress activation frequency [10].

The reduction in the size of the BMU resorption cavities due to bisphosphonate treatment was also simulated by reducing the area resorbed. Starting with the control cement line radius of $0.198 \mathrm{~mm}$, different resorption cavity areas ranging from $100 \%$ of control or no reduction, down to $50 \%$ of the control were evaluated to model bisphosphonate treatment:

area_ $r=\left(\pi R_{c}^{2}\right) *$ percent_area_reduced.

After testing all combinations of $\mathrm{P}_{\max }(0-1)$, tau (1-20), and the percent area reduced (0.51) for bisphosphonate treatment, a $\mathrm{P}_{\max }=0.3$, a tau $=1$, and a resorption area of 0.67 of the control value was used for ALN0.2 and a $\mathrm{P}_{\max }=0.2$, a tau $=1$, and a resorption area of 0.625 was used for ALN1.0. These values were used because the results from these combinations were found to be most closely within range of the BV/TV, Ac.f, and microdamage for the experimental 1 and 3 years of bisphosphonate treatment for each dosage.

Numerical implementation. The computational model was implemented in MATLAB (Appendix A). This constitutive model relates two differential equations [Eqs. (9) and (14)] together for porosity and damage, respectively [19]. The mechanical stimulus $\Phi$ is the independent external force governing the model while the BMU activation frequency is dependent on $\Phi$, along with the damage and the porosity [Eqs. (10), (12), and (13)]. Previous studies have implemented a similar model using different numerical methods including the forward Euler method, and varying the time increments between 0.05 to 8 days; however, the current numerical method was deemed sufficient for the present 
model. Using time steps smaller than 1 day did not significantly improve the accuracy, therefore, an iteration period of $\mathrm{t}=1$ day was used for this model because bisphosphonates are taken up fairly quickly [10].

\subsection{Statistical Analysis}

To assess the dependence of the experimental bisphosphonate treatments for 1 and 3 years, statistical analyses was performed to determine if there were variations between the treatment groups. Using Minitab (Minitab Inc.; State College, PA), a oneway analysis of variance (ANOVA) was performed for bone volume fraction, activation frequency, and microdamage for 1 and 3 years to compare treatment groups. P-values less than 0.05 were considered statistically significant and signified that there was a significant difference between the treatment groups. After completing an ANOVA, a Tukey post-hoc test was performed to compare individual pairs of treatment groups to determine where the significant difference lies between the paired means.

A one sample t-test analysis was performed to compare the measured data to the simulated result for each treatment groups of bone volume fraction, activation frequency, and microdamage. These results indicate whether the differences between the values are statistically significant. The null hypothesis was that the simulated results were equal to the measured results and was rejected for $\mathrm{p}<0.05$. 


\section{CHAPTER 3: RESULTS}

\subsection{Experimental Bone Volume Fraction Measurements}

After measuring the porosity of each of the seventy-two sample slides using Bioquant, the bone volume fraction $(\mathrm{BV} / \mathrm{TV}=1-$ porosity) was calculated. Because two sections were cut from each of the thirty-six bone samples, the average BV/TV of each sample was calculated and is listed in Table 5 with its treatment group. The final BV/TV values for each treatment group are summarized in Table 6 . These results were calculated by taking the mean with standard deviations of all the data from each of the three treatment groups. 
Table 5. Measured 3 year data by treatment for bone volume fraction (BV/TV)."

\begin{tabular}{|c|c|c|}
\hline Sample \# & Treatment & BV/TV \\
\hline 60809 & ALN1.0 & 0.9745 \\
\hline 60750 & ALN1.0 & 0.9743 \\
\hline 59244 & ALN1.0 & 0.9595 \\
\hline 59230 & ALN0.2 & 0.9534 \\
\hline 59210 & CON & 0.9612 \\
\hline 59234 & CON & 0.969 \\
\hline 59238 & ALN1.0 & 0.9618 \\
\hline 59211 & ALN1.0 & 0.9695 \\
\hline 59235 & ALN0.2 & 0.9724 \\
\hline 59257 & CON & 0.9674 \\
\hline 59219 & ALN0.2 & 0.9618 \\
\hline 59315 & CON & 0.9592 \\
\hline 59256 & ALN0.2 & 0.9592 \\
\hline 59258 & ALN0.2 & 0.9677 \\
\hline 59231 & ALN1.0 & 0.9636 \\
\hline 59236 & ALN1.0 & 0.9558 \\
\hline 60657 & ALN1.0 & 0.9589 \\
\hline 60628 & CON & 0.9717 \\
\hline 60034 & CON & 0.9654 \\
\hline 60592 & ALN0.2 & 0.9677 \\
\hline 59536 & ALN1.0 & 0.9596 \\
\hline 60642 & ALN0.2 & 0.9783 \\
\hline 60593 & ALN1.0 & 0.958 \\
\hline 60636 & ALN0.2 & 0.9685 \\
\hline 59677 & CON & 0.9662 \\
\hline 60630 & CON & 0.9729 \\
\hline 60707 & CON & 0.9678 \\
\hline 60629 & ALN0.2 & 0.9615 \\
\hline 60631 & ALN0.2 & 0.973 \\
\hline 59239 & ALN0.2 & 0.9639 \\
\hline 60641 & ALN1.0 & 0.9751 \\
\hline 60632 & CON & 0.9767 \\
\hline 60643 & ALN1.0 & 0.9597 \\
\hline 60645 & ALN0.2 & 0.9697 \\
\hline 60644 & CON & 0.9631 \\
\hline 60667 & CON & 0.9675 \\
\hline
\end{tabular}

${ }^{*}$ Unpublished measured data 
Table 6. Mean \pm SD for the measured 3 year data.

\begin{tabular}{|c|c|c|c|}
\hline & CON (1ml/kg/day) & $\begin{array}{c}\text { Alendronate (0.20 } \\
\mathbf{m g} / \mathbf{k g} / \mathbf{d a y})\end{array}$ & $\begin{array}{c}\text { Alendronate 1.00 } \\
\mathbf{m g} / \mathbf{k g} / \text { day })\end{array}$ \\
\hline $\begin{array}{c}\text { Bone volume } \\
\text { fraction (BV/TV) }\end{array}$ & $.96754 \pm 0.00489$ & $.96642 \pm 0.00683$ & $.96415 \pm 0.00718$ \\
\hline
\end{tabular}

\subsection{Simulation Bone Volume Fraction Results}

For the simulation, the bone volume fraction (BV/TV) for both doses of alendronate (ALN0.2 mg/kg/day and ALN1.0 mg/kg/day) remained fairly constant throughout the 3 years of bisphosphonate treatment as was expected from the experimental data. Figure 17 illustrates graphs for 1 and 3 years of ALN0.2 and ALN1.0 treatment groups. Although 1 year experimental control data was not obtained from the Indiana University School of Medicine, 3 year experimental control results were used instead because 1 and 3 year bone volume values were assumed to be similar. The model's results for the bone volume percentage were consistent with the experimental data (Table 7). All simulated results matched within one standard deviation of the measured values.

Table 7. Model simulation and experimental measurements for bone volume fraction of the canine rib bone after 1 and 3 years by treatment.

\begin{tabular}{|c|c|c|c|c|}
\cline { 2 - 5 } \multicolumn{1}{c|}{} & \multicolumn{4}{c|}{ Bone Volume Fraction } \\
\cline { 2 - 5 } \multicolumn{1}{c|}{} & \multicolumn{2}{c|}{ year } & 3 years \\
\cline { 2 - 5 } \multicolumn{1}{c|}{ Experimental } & Simulated & Experimental & Simulated \\
\hline CON & $0.968 \pm 0.00489$ & 0.9651 & $0.968 \pm 0.00489$ & 0.9651 \\
\hline ALN0.2 & $0.966 \pm 0.00683$ & 0.9649 & $0.966 \pm 0.00683$ & 0.9651 \\
\hline ALN1.0 & $0.964 \pm 0.00718$ & 0.9649 & $0.964 \pm 000.718$ & 0.9651 \\
\hline
\end{tabular}




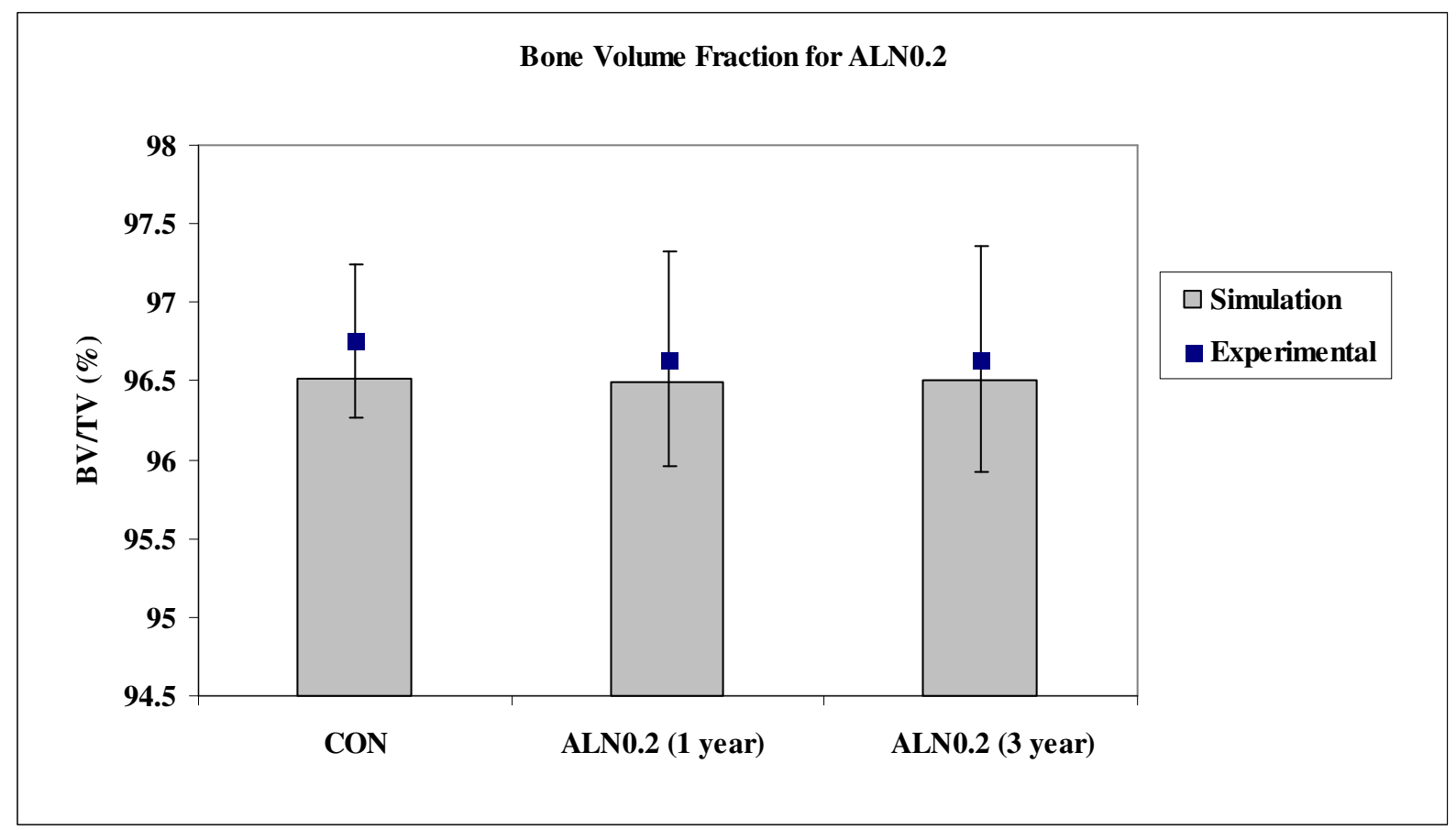

b.



Figure 17. Simulation and experimental measurement results (mean and SD) for BV/TV for (a) control (CON) and ALN0.2 at 1 and 3 years and (b) control (CON) and ALN1.0 at 1 and 3 years. 


\subsection{Simulation Activation Frequency Results}

The results of the computational model for the control and 1 year cortical rib data for the activation frequency were consistent with experimental measurements (Table 8). The model was able to predict the 1 year experimental results for both ALN0.2 and ALN1.0 along with the experimental results for ALN1.0 at 3 years, but overestimated the results for ALN0.2 at 3 years. In the simulation, alendronate suppressed activation frequency for bone remodeling for both doses of drug and remained fairly constant over the span of 3 years of treatment. While the simulation predicted that activation frequency remains mainly constant over the 3 years, the experiments show decreases between 1 and 3 years. Although not to a great degree, remodeling was suppressed in the model almost immediately after bisphosphonate treatment was introduced. By 1.5 years, activation frequency had reached near constant for both alendronate doses. The representative graphs of both the simulated and experimental treatment data with its corresponding error bars can be seen in Figures 18.

Table 8. Model simulation and experimental measurements for activation frequency of the canine rib bone after 1 and 3 years of ALN treatment.

\begin{tabular}{|c|c|c|c|c|}
\cline { 2 - 5 } \multicolumn{1}{c|}{} & \multicolumn{4}{c|}{ Activation Frequency $\left(\mathbf{B M U s} / \mathbf{m m}^{2} /\right.$ day $)$} \\
\cline { 2 - 5 } \multicolumn{1}{c|}{ 1 year } & Simulated & Experimental & Simulated \\
\cline { 2 - 5 } & Experimental & 0.0098 & $0.00902 \pm 0.0077$ & 0.0098 \\
\hline CON & $0.0384 \pm 0.0290$ & 0.009698 & $0.00153 \pm 0.00215$ & 0.0099 \\
\hline ALN0.2 & $0.0361 \pm 0.0322$ & 0.009698 & $0.00521 \pm 0.00792$ & 0.01 \\
\hline ALN1.0 & $0.0202 \pm 0.0134$ & \multicolumn{3}{c}{} \\
\hline
\end{tabular}


a.



b.

Activation Frequency for ALN1.0

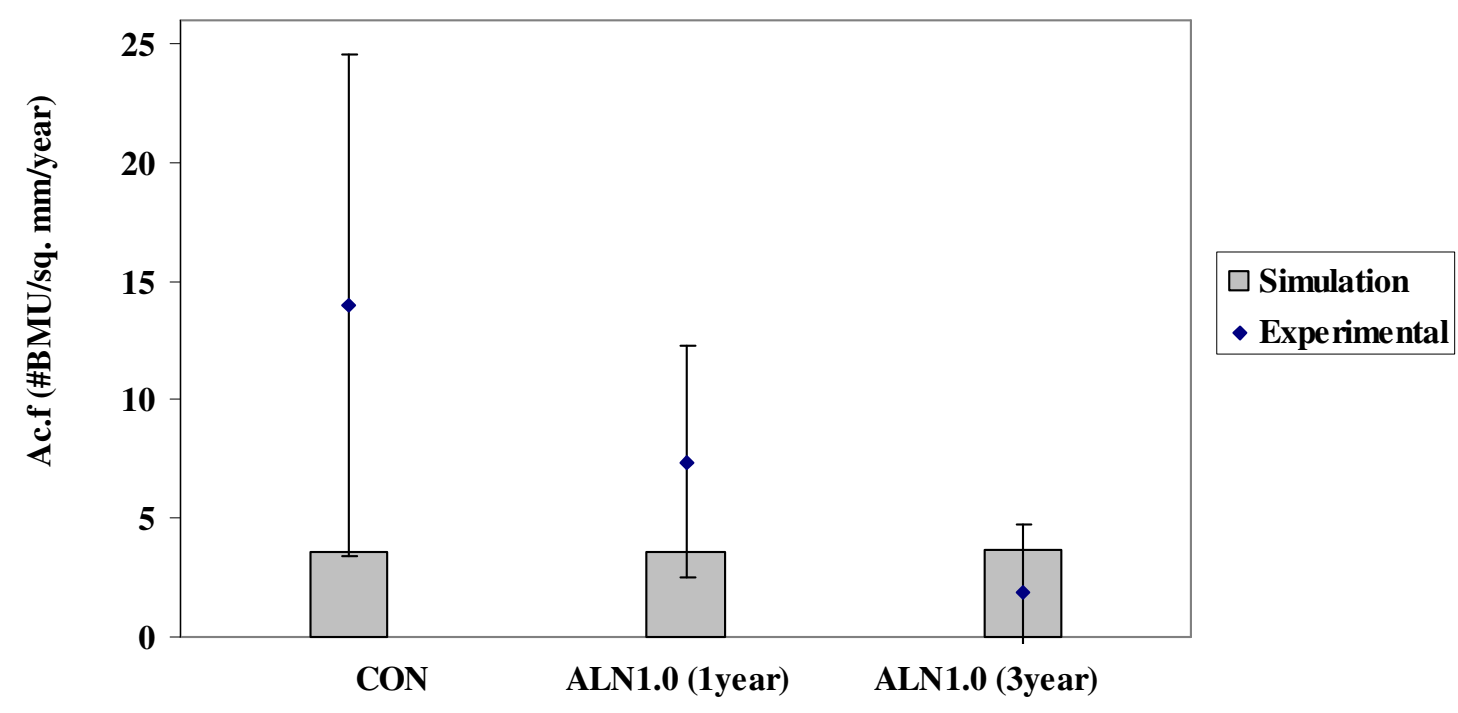

Figure 18. Simulation and experimental measurement results (mean and SD) activation frequencies for (a) control (CON) and ALN0.2 for 1 and 3 years or treatment and (b) control (CON) and ALN1.0 for 1 and 3 years of treatment. 


\subsection{Simulation Microdamage Results}

The results of the computational model for the control, 1, and 3 year rib data for microdamage were consistent with experimental measurements (Table 9). The model was able to predict an initial increase in damage for both bisphosphonate treatment doses before leveling off slightly after 1 year (Figure 19). Microdamage begins to increase almost immediately after bisphosphonate treatment with a percent increase of 51.2\% (ALN0.2) and 58.9\% (ALN1.0) from the start of initiating bisphosphonate treatment (CON) to 3 years of treatment. For ALN0.2, the modeled results show a percent increase of $8.3 \%$ from 1 to 3 years of bisphosphonate treatment and for ALN1.0, the modeled results show a percent increase of $10.2 \%$ from 1 to 3 years of bisphosphonate treatment. Although the simulated damage is not as high as the damage obtained from the experimental data, the overall trend correlates with experimental data which showed that the increase in microdamage at 3 years was not significantly different compared to the 1 year results. Both experimental and simulated microdamage results are shown for 1 and 3 years of alendronate treatment in Table 9. A condensed table of all parameters of interest (BV/TV, Ac.f, and damage) can be found in Appendix B.

Table 9. Model simulation and experimental microdamage measurements in the canine rib bone after 1 year and 3 years of ALN treatment.

\begin{tabular}{|c|c|c|c|c|}
\cline { 2 - 5 } \multicolumn{1}{c|}{} & \multicolumn{4}{c|}{ Microdamage $\left(\mathbf{m m} / \mathbf{m m}^{2}\right)$} \\
\cline { 2 - 5 } \multicolumn{1}{c|}{} & Experimental & Simulated & Experimental & Simulated \\
\cline { 2 - 5 } & $0.0169 \pm 0.0189$ & 0.0129 & $0.0248 \pm 0.0280$ & 0.0129 \\
\hline CON & $0.0326 \pm 0.0339$ & 0.018 & $0.0449 \pm 0.0273$ & 0.0195 \\
\hline ALN0.2 & $0.0332 \pm 0.0393$ & 0.0187 & $0.0408 \pm 0.0216$ & 0.0206 \\
\hline ALN1.0 & \multicolumn{3}{c}{} \\
\hline
\end{tabular}


a.

Microdamage for ALN0.2



b.

Microdamage for ALN1.0



Figure 19. Experiment (mean \pm SD) and simulation graphs for damage with bisphosphonate treatment starting at $t=0$ (a) ALNO.2, (b) ALN1.0 


\subsection{Statistical Analysis}

A one-way ANOVA was performed on the bone volume fraction, activation frequency, and microdamage to test for significant differences between experimental treatment groups. An ANOVA was only performed for experimental treatment groups so that any variation in the experimental results could be noted. The results are displayed in Table 10 and Table 11 for the ANOVA.

Table 10. 1 year ANOVA results for measured activation frequency and damage by treatment

\begin{tabular}{|c|c|c|c|c|}
\cline { 2 - 5 } \multicolumn{1}{c|}{} & CON & ALN0.2 & ALN1.0 & P \\
\hline $\begin{array}{c}\text { Activation Frequency } \\
\text { (BMUs/mm } / \text { year) }\end{array}$ & $0.0384 \pm 0.0290$ & $0.0361 \pm 0.0322$ & $0.0202 \pm 0.0134$ & 0.196 \\
\hline Damage $\left(\mathbf{m m} / \mathbf{m m}^{2}\right)$ & $0.0169 \pm 0.0189$ & $0.0326 \pm 0.0339$ & $0.0332 \pm 0.0393$ & 0.374 \\
\hline
\end{tabular}

Table 11. 3 year ANOVA results for measured bone volume fraction, activation frequency, and damage by treatment

\begin{tabular}{|c|c|c|c|c|}
\hline & $\mathrm{CON}$ & ALN0.2 & ALN1.0 & $\mathbf{P}$ \\
\hline Bone Volume Fraction & $0.968 \pm 0.00489$ & $0.966 \pm 0.00683$ & $0.964 \pm 0.00718$ & 0.426 \\
\hline $\begin{array}{c}\text { Activation Frequency } \\
\text { (BMUs/mm²/year) }\end{array}$ & $0.00901 \pm 0.0271$ & $0.00153 \pm 0.00215$ & $0.00521 \pm 0.00792$ & 0.0286 \\
\hline Damage $\left(\mathbf{m m} / \mathbf{m m}^{2}\right)$ & $0.0228 \pm 0.271$ & $0.0449 \pm 0.0273$ & $0.0408 \pm 0.216$ & 0.0914 \\
\hline
\end{tabular}

All p-values for 1 year of alendronate treatment were greater than 0.05 which indicates that the variation between treatment groups were not significant. The p-values for 3 year alendronate treatment showed that there is a significant difference between the treatment groups for the activation frequency which had a p-value of 0.0286 . To determine where the difference lies between each treatment, individual Tukey 
comparisons were performed for the 3 year activation frequency. The p-values for the Tukey comparisons show that the difference in treatment group found in the ANOVA test lies in the CON/ALN0.2 comparison with a $\mathrm{p}=0.0039$. The results for the Tukey comparisons are presented in Table 12.

Table 12. P-values for individual Tukey comparison for activation frequency for 3 years of treatment.

\begin{tabular}{|c|c|}
\hline Comparisons & P \\
\hline CON and ALN0.2 & 0.0039 \\
\hline CON and ALN1.0 & 0.2472 \\
\hline ALN0.2 and ALN1.0 & 0.1337 \\
\hline
\end{tabular}

A separate comparison between the experimental results of ALN0.2 and ALN1.0 for 1 and 3 years for activation frequency shows that all p-values are less than 0.05 which indicates that the 1 and 3 year data for both treatment groups are significantly different (Table 13). A comparison between the experimental results for ALN0.2 and ALN1.0 for 1 and 3 years for microdamage found that all p-values were greater than 0.05 which signifies that the 1 year experimental data is similar to the 3 year experimental data for each treatment group (Table 14).

Table 13. P-values for activation frequency comparing 1 and 3 year experimental values.

\begin{tabular}{|c|c|}
\hline Comparisons & P \\
\hline 1 year CON vs 3 year CON & 0.0026 \\
\hline 1 year ALN0.2 vs 3 year ALN0.2 & 0.0012 \\
\hline 1 year ALN1.0 vs 3 year ALN1.0 & 0.0029 \\
\hline
\end{tabular}


Table 14. P-values for damage comparing 1 and 3 year experimental values.

\begin{tabular}{|c|c|}
\hline Comparisons & P \\
\hline 1 year CON vs 3 year CON & 0.5427 \\
\hline 1 year ALN0.2 vs 3 year ALN0.2 & 0.3365 \\
\hline 1 year ALN1.0 vs 3 year ALN1.0 & 0.5651 \\
\hline
\end{tabular}

A one sample t-test analysis was performed to compare the measured experimental values to the simulated results for bone volume fraction, activation frequency, and damage. The null hypothesis for each of the following t-tests was that the measured experimental value is equal to the simulated results, which represents the mean value. For the bone volume fraction, the p-value of all treatment groups (CON, ALN0.2, and ALN1.0) for 1 and 3 years of treatment was greater than 0.05 so the null was not rejected, which implies that the measured and simulated results are statistically similar for all treatment groups (Table 15).

Table 15. P-values for t-test for bone volume fraction for 1 and 3 years by treatment.

\begin{tabular}{|c|c|c|}
\cline { 2 - 3 } \multicolumn{1}{c|}{} & $\mathbf{1}$ year & $\mathbf{3}$ years \\
\cline { 2 - 3 } & $\mathbf{P}$ & $\mathbf{P}$ \\
\hline CON & 0.112 & 0.112 \\
\hline ALN0.2 & 0.458 & 0.518 \\
\hline ALN1.0 & 0.726 & 0.657 \\
\hline
\end{tabular}

T-tests for the 1 year CON group for activation frequency resulted in a $\mathrm{p}<0.05$ suggesting that there is a significant difference between the measured and simulated values with the 1 year experimental results being higher than the 1 year modeled result. 
Similarly, a p value less than 0.05 was found for the ALN0.2 treatment group for 1 and 3 years of treatment and for the ALN1.0 treatment group for 1 year (Table 16). The null hypothesis was rejected for these cases. The 3 year ALN1.0 treatment group for activation frequency resulted in a $p>0.05$ indicating a similarity between the measured and simulated results, so the null hypothesis was not rejected.

Table 16. P-values for t-test for activation frequency for 1 and 3 years by treatment.

\begin{tabular}{|c|c|c|}
\cline { 2 - 3 } \multicolumn{1}{c|}{} & $\mathbf{1}$ year & $\mathbf{3}$ years \\
\cline { 2 - 3 } \multicolumn{1}{c|}{} & $\mathbf{P}$ & $\mathbf{P}$ \\
\hline CON & 0.006 & 0.7324 \\
\hline ALN0.2 & 0.016 & 0.0001 \\
\hline ALN1.0 & 0.02 & 0.06 \\
\hline
\end{tabular}

T-test results for microdamage (Table 17) yielded p values greater than 0.05 for all 1 year treatment groups and the $\mathrm{CON}$ at 3 years, which indicate that the null was not rejected and that the measured and simulated results are statistically similar. For ALN0.2 and ALN1.0 treatment groups at 3 years, $\mathrm{p}=0.008$, which implies that there is a significant difference between the measured and simulated results for both cases with the experimental damage result higher than the modeled result for both treatment groups. 
Table 17. P-values for $t$-test for damage for 1 and 3 years by treatment.

\begin{tabular}{|c|c|c|}
\cline { 2 - 3 } \multicolumn{1}{c|}{} & $\mathbf{1}$ year & $\mathbf{3}$ years \\
\cline { 2 - 3 } \multicolumn{1}{c|}{} & $\mathbf{P}$ & $\mathbf{P}$ \\
\hline CON & 0.484 & 0.2335 \\
\hline ALN0.2 & 0.164 & 0.008 \\
\hline ALN1.0 & 0.227 & 0.008 \\
\hline
\end{tabular}




\section{CHAPTER 4: DISCUSSION}

Osteoporosis is a skeletal disease that occurs when the amount of bone resorption exceeds that of bone formation. Without treatment, bone becomes more porous and fracture risk is increased. Bisphosphonates are commonly used to treat bone diseases such as osteoporosis by reducing resorption activity [17]. The objective of this study was to modify a previous mathematical model for bone remodeling which incorporated a bisphosphonate algorithm, in order to simulate the effects of alendronate on canine rib remodeling and microdamage after 1 and 3 years of treatment. To do so, empirical data for 1 and 3 year studies were supplied by Allen et al. [24, 30] from the Indiana University School of Medicine, and utilized to confirm the accuracy of the model. The current study uses the results from the control experimental data for dog ribs as a baseline to create a model that simulates the effects of ALN for a 3 year period. The importance of developing a model is to predict long term outcomes without having to carry out long term experimental tests. Because canine bone remodeling dynamics are similar to human bone remodeling, this canine model can be used to draw parallels to the drugs effects on human bones [32].

\subsection{Bone Volume Fraction}

The model predicts a slight increase in the bone volume fraction for both treatment doses from one to three years. The results comply with the original assumption that the 1 and 3 year experimental data were similar, which allowed the three year bone 
volume measurements to be used in place of the one year data. To validate this assumption, an ANOVA test was performed between experimental treatment groups (CON, ALN0.2, and ALN1.0). The p-value of 0.426 indicates that the results from each treatment group are not significantly different. Results from the computer model indicate that the BV/TV for both doses of alendronate was fairly constant throughout the 3 years of bisphosphonate treatment and the simulation was able to successfully match all experimental data within one standard deviation. The small increase from one to three years of treatment denotes a decrease in the bone's porosity which is due to the suppression of osteoclast activity. This is consistent with studies that have shown an increase in bone mass following treatments of bisphosphonate [10].

\subsection{Activation Frequency}

The model results for activation frequency for the control, 1 year ALN0.2 and ALN1.0, and 3 year ALN1.0 were within range of the experimental data; however, activation frequency for ALN0.2 for 3 years was not consistent with the experimental measurements. As predicted by past experimental studies, bisphosphonate usage suppressed bone remodeling for both modeled doses of alendronate. While the simulation was able to show decreases in bone remodeling for both treatment doses after 1 year of treatment, the decrease was not nearly as drastic as the results seen in the experimental study and remained fairly constant between 1 and 3 years, which is in contrast to the experimental results. Despite this, the model was able to match all but one of the experimental data, which overestimated ALN0.2 for the three years of treatment. The one-way ANOVA for activation frequency for 3 years of treatment found that there 
was a discrepancy between the three treatment groups (CON, ALN0.2, and ALN1.0) with a p-value less than 0.05 . This result shows that there is a statistically significant difference between the 3 year experimental treatment groups and that there is less than a $5 \%$ chance of obtaining these results assuming the null hypothesis is true. Performing a Tukey comparison between individual 3 year experimental treatment groups showed that the difference came from the control group. The current model predicts that the activation frequency for the 1 and 3 year control treatment is similar and did not account for the actual change seen in the experimental measurements. The unpublished 3 year study by Burr et al. [24] obtained a control activation frequency of 0.00901 $\mathrm{BMUs} / \mathrm{mm}^{2} /$ day, which is 4 times less than the 1 year control activation frequency used for the model $\left(0.03841 \mathrm{BMUs} / \mathrm{mm}^{2} / \mathrm{day}\right)$. This disparity in 1 and 3 year control values may explain some of the inconsistencies of the model results. The one-sample t-test statistical analysis determined that 3 year CON and ALN1.0 for the measured and simulated results are similar; however, all 1 year treatment groups (CON, ALN0.2, and ALN1.0) and the 3 year ALN0.2 for the measured and simulated results are statistically different with p-values less than 0.05. Although the 1 year measured and simulated results were found to be statistically different, all 1 year modeled results were within 1 standard deviation of the experimental results.

\subsection{Microdamage Accumulation}

The effect of bisphosphonates on microdamage accumulation has been a major issue concerning the long term use of the drug because increases in microdamage can lead to bone fragility. Studies have shown a relationship between the suppression of 
bone remodeling and microdamage accumulation over a treatment period of 1 year [17, 33]. Because patients generally undergo osteoporosis treatment drugs for longer than 1 year, it is important to determine the effects of the drug for a longer time period. Three year studies performed by Allen et al. $[18,24]$ show that although treatment group microdamage levels increase above the control group, damage does not significantly increase after 1 year of alendronate treatment. The computer model predicts that damage accumulation is greatest early during bisphosphonate treatment, due to the initial suppression of bone resorption, and eventually reaches a new equilibrium level after 1 year. Although the increase in damage is not as high as the measured results, the overall shape of the curve is consistent. The increase in damage was previously thought to impair the mechanical properties of bone [34]; however, recent experimental studies show that while the initial increase in microdamage may contribute to alterations in bone properties at 1 year of treatment, other factors like increased mineralization and bone volume appear to impede the harmful effects of damage accumulation in the long run [24]. The simulation results are consistent with the experimental data, which suggest that damage increases up to 1 year of treatment and then levels off thereafter. The results of the simulation suggest that since bisphosphonates do not cause a further increase in microdamage accumulation after 1year of treatment, ALN may not lead to increased bone fragility associated with microdamage long term. These results are seen in 3 year experimental studies as well.

Logically, it makes sense that microdamage increases until a new equilibrium is reached between the amount of damage formation and damage removal because bisphosphonates inhibit bone remodeling. The computational model results for the 1 and 
3 year rib data for all treatment groups were consistent with experimental measurements. One-sample t-test statistical analyses confirm that the simulated 1 year microdamage results for the CON, ALN0.2, and ALN1.0 treatment groups were similar to the 1 year experimental measurements with $\mathrm{p}>0.05$. The 3 year simulated control group also showed similarities to the 3 year experimental control; however, the t-tests for the three year ALN0.2 and ALN1.0 treatment groups rejected the null hypothesis with $\mathrm{p}$ values less than 0.05. Although the ALN0.2 and ALN1.0 treatment groups did not satisfy the null hypothesis in this case, as observed in the graph (Figure 13), both results are within 1 standard deviation of the experimental measurement data.

\subsection{Limitations and Future Model Considerations}

The present study was able to simulate the effects of alendronate treatment on bone remodeling; however, limitations to the model must be considered when interpreting the results. Although the general mechanisms of bisphosphonate are simulated in the model, the entire range of the drugs response is not taken into account due to its complexity and the lack of understanding of the exact mechanism of action that bisphosphonates have in the body. Theoretical models require many of assumptions and guesswork which involve verifying the results of the model with experimental data.

As indicated by Hernandez et al. [16], bone mineralization is a major contributor of increases in BMD than simply decreasing area resorbed as done in the current model. Bisphosphonate treatment reduces the bone turnover rate in bone which allots more time for mineralization to take place thus allowing secondary mineralization to play an important role in BMD. By limiting the number of osteoclasts that resorb bone, bone is 
allowed more time to mineralize before being resorbed thus resulting in increases in bone mass. Because changes in resorption area and mineralization are both factors in increased BMD, future models should include both methods when determining the effects of bisphosphonates on bone remodeling.

Another possible improvement is the elastic modulus and the bone volume fraction relationship. For the current model, the equation was estimated using only the empirical data given for the 3 year bisphosphonate dog rib study. If more information was available for the 1 year experimental studies including the elastic modulus and the bone volume fractions from each treatment group, the modulus-BV/TV relationship could be improved by comparing the 1 and 3 year results and creating a more accurate relationship.

The current model assumes that the ability of BMUs to target damage removal or the specificity factor $\mathrm{f}_{\mathrm{s}}$ is constant; but, this is not necessarily accurate since areas of resorption with microdamage have been shown to be reduced with alendronate treatment [10]. If $\mathrm{f}_{\mathrm{s}}$ were to be varied according to the microcrack initiation, damage removal may decrease compared to the current results.

Also, bone formation was assumed to be normal prior to bisphosphonate treatment. However, this does not accurately represent osteoporotic bone which corresponds to higher levels of bone resorption and a decrease in bone formation. Modeling osteoporotic bone from the start could greatly improve the current model. Another limitation of the current model is that it was assumed that the control experimental result for bone volume fraction, activation frequency, and microdamage were assumed to be the same for 1 and 3 year. In actuality, the control for 1 and 3 year 
experimental studies vary greatly. This assumption will affect the modeled activation frequency result most, as this 3 year experimental control varied greatly compared to the 1 year experimental control data. The model would significantly benefit by modifying the program to take this into account. By allowing the simulation to reach the three year experimental control, the 3 year model results may improve and more accurately represent the 3 year experimental results.

Furthermore, the current study only simulates remodeling under a constant applied stress in a representative section of bone rather than modeling the entire rib bone or developing finite element models that could allow a more accurate remodeling response by allowing more precise loading conditions and provide better analysis of different strain rates on different sections of bone. Making these modifications in the model could greatly improve future understanding of bisphosphonates and its long term effects on bone.

\subsection{Conclusion}

The goal of the study is to develop a computational model to determine the effects of bisphosphonate treatment on remodeling dynamics by matching the results of 1 and 3 year experimental data for bone remodeling and damage in a canine rib model. The results from the simulation are as follows:

- Previous experimental studies have shown that bisphosphonate treatment reduces fracture risk by increasing bone mass $[17,33]$. The model predicted a slight increase in bone volume fraction for both doses (ALN0.2 and ALN1.0) of bisphosphonate treatment over a three year period. 
- The purpose of taking alendronate is to reduce bone porosity by decreasing bone resorption. Bisphosphonates do this by suppressing osteoclast activity and in effect bone remodeling which decreases the activation frequency as shown in the model.

Although the degree of reduction in activation frequency for the computer model did not match the value seen in the experiments, 1 and 3 year ALN1.0 and 3 year ALN1.0 treatment doses were within range of the measured results.

- Because bisphosphonates suppress bone remodeling, microdamage accumulation has been shown to increase at 1 year of treatment [17, 18, 24, 33]; however, 3 year experimental results show that although microdamage increases after initial bisphosphonate treatment, damage does not continue to increase and rather reaches a plateau after around 1 year.

The model was able to reflect the recent 3 year canine studies performed by Allen et al. [18, 24]. All simulated model results for microdamage support the findings obtained from previous experimental studies.

Future experimental studies investigating longer time periods of bisphosphonate treatment are necessary in order to enhance and validate the computer model to better predict the long term effects of bisphosphonate usage. Longer experimental studies are also needed to better understand the relationship between bone remodeling suppressant drugs and bone health. Improved computational models are also beneficial to more accurately predict bone remodeling. This is important in order to ensure that the long 
term effects of alendronate treatment are safe and effective for the use in osteoporotic patients. These simulations will help in developing improved methods of predicting bisphosphonate treatment on bone as well as determine if the long term effects of bisphosphonate usage will indeed increase bone mass and reduce fracture risk. The understanding of the effects of bisphosphonate treatment on dog ribs can also aid in developing better models to simulate the effects of bisphosphonate treatment in humans. 


\section{REFERENCES}

[1] Seeley RR, Stephens TD, Tate P. Anatomy \& Physiology. New York: McGraw Hill Company, Sixth Edition, 2003.

[2] Martin RB, Burr DB, Sharkey NA. Skeletal Tissue Mechanics. New York: Springer; 1998.

[3] Basic Bone Biology. 2007. International Osteoporosis Foundation. 5 March 2009 $<$ http://www.iofbonehealth.org/health-professionals/about-osteoporosis/basicbone-biology.html>.

[4] Structure of Bone Tissue. 2000. Seer's Training Website. 5 March 2009 $<$ http://training.seer.cancer.gov/module_anatomy/unit3_2_bone_tissue.html\#>.

[5] Guyton AC, Hall JR. Textbook of Medical Physiology. Pennsylvania: Elsevier Inc, Eleventh Edition, 2006.

[6] Osteoporosis. 2007. A.D.A.M. Medical Encyclopedia. 5 March 2009 <http://www.nlm.nih.gov/medlineplus/ency/imagepages/17285.htm>.

[7] Earnshaw SR, Graham CN, Ettinger B, Amonkar MM, Lynch NO, Middelhoven H. Cost-effectiveness of Bisphosphonate Therapies for Women with Postmenopausal Osteoporosis: Implications of Improved Persistence with Less Frequently Administered Oral Bisphosphonates. Current Medical Research and Opinion 2007; 23.10: 2517-2529.

[8] Rosen CJ. Postmenopausal Osteoporosis. The New England Journal of Medicine 2005; 353: 595-603.

[9] Komatsubara S, Mori S, Mashiba T, Li J, Nonaka K, Kaji Y, Akiyama T, Miyamoto K, Cao Y, Kawanishi J, Norimatsu H. Suppressed Bone Turnover by Long-Term Bisphosphonate Treatment Accumulates Microdamage but Maintains Intrinsic Material Properties in Cortical Bone of Dog Rib. Journal of Bone and Mineral Research 2004; 19: 999-1005.

[10] Nyman JS, Yeh OC, Hazelwood SJ, Martin RB. A theoretical analysis of long term bisphosphonate effects on trabecular bone volume and microdamage. Bone 2004; 35:296-305.

[11] Graham R. Determinants of Structure-Function Relationships among Bisphosphonates. Bone 2007; 40:521-525. 
[12] Kimmel DB. Mechanism of Action, Pharmacokinetic and Pharmacodynamic Profile,and Clinical Applications of Nitrogen-Containing Bisphosphonates. Journal of Dental Research 2007; 86.11: 1022-33.

[13] Weinberg MA. Bisphosphonate-Associated Osteonecrosis of the Jaws: Impact on Oral Health. 2006. U.S. Pharmacist: 62-69. 5 March 2009 $<$ http://www.uspharmacist.com/content/d/featured_articles/c/11662/>.

[14] Silverman SL, Maricic M. Recent Developments in Bisphosphonate Therapy. Seminars in Arthritis Rheumatism 2007; 37:1-12.

[15] Rodan GA, Fleisch HA. Bisphosphonates: Mechanism of Action. Journal of Clinical Investigation 1996; 97.12: 2692-2696.

[16] Hernandez CJ, Beaupré GS, Marcus R, Carter DR. A theoretical analysis of the contributions of remodeling space, mineralization, and bone balance to changes in bone mineral density during alendronate treatment. Bone 2001; 29: 511-6.

[17] Allen MR, Iwata K, Phipps R, Burr DB. Alterations in Canine Vertebral Bone Turnover, Microdamage Accumulation, and Biomechanical Properties Following 1 Year Treatment with Clinical Treatment Doses of Risedronate or Alendronate. Bone 2006; 39.4: 872-79.

[18] Allen MR, Burr DB. Three Years of Alendronate Treatment Results in Similar Levels of Vertebral Microdamage as after One Year of Treatment. Journal of Bone and Mineral Research 2007; 22: 1759-65.

[19] Hazelwood SJ, Martin RB, Rashid MM, Rodrigo, JJ. A mechanistic model for internal bone remodeling exhibits different dynamic responses in disuse and overload. Journal of Biomechanics 2001; 34:299-308.

[20] Carter DR, Fyhrie DP, Whalen RT. Trabecular bone density and loading history: regulation of connective tissue biology by mechanical energy. Journal of Biomechanics 1987; 20:785-94.

[21] Huiskes R, Weinans H, Grootenboer HJ, Dalstra M, Fudala B, Slooff TJ. Adaptive bone-remodeling theory applied to prosthetic-design analysis. Journal of Biomechanics 1987; 20:1135-50.

[22] Martin RB. Mathematical model for repair of fatigue damage and stress fracture in osteonal bone. Journal of Orthopaedic Research 1995; 13: 309-316.

[23] Heaney RP, Yates AJ, Santora II AC. Bisphosphonate effects and the bone remodeling transient. Journal of Bone and Mineral Research 1997; 12:6-15. 
[24] Allen MR, Reinwald S, Burr DB. Alendronate reduces bone toughness of ribs without significantly increasing microdamage accumulation in dogs following three years of daily treatment. Calcified Tissue International 2008; 82: 354-360.

[25] Burr, DB, Martin, RB. Calculating the probability that microcracks initiate resorption spaces. Journal of Biomechanics1993; 26:613-616.

[26] Hart RT, Davy DT. Theories of bone modeling and remodeling. Bone Mechanics. Boca Raton, FL: CRC Press; 1989, pp.253-77.

[27] Martin RB. The usefulness of mathematical models for bone remodeling. Yearbook of Physical Anthropology 1985; 28:227-36.

[28] Martin RB. Porosity and specific surface of bone. Critical Reviews in Biomedical Engineering 1984; 10:179-222.

[29] Frost HM. Tetracycline-based histological analysis of bone remodeling. Calcified Tissue Research 1969; 3:211-37.

[30] Allen MR, Follet H, Khurana M, Sato M, Burr DB. Antiremodeling Agents Influence Osteoblast Activity Differently in Modeling and Remodeling Sites of Canine Rib. Calcified Tissue International 2006; 79:255-261.

[31] McCullough S. Beagles for Dummies. Wiley Publishing Inc. 2006.

[32] Jaworski ZF, Lok E. The Rate of Osteoclastic Bone Erosion in Haversian Remodeling Sites of Adult Dog's Rib. Calcified Tissue Research 1972; 10: 103112.

[33] Mashiba T, Hirano T, Turner CH, Forwood MR, Johnston CC, Burr DB. Suppressed Bone Turnover by Bisphosphonates Increases Microdamage Accumulation and Reduces Some Biomechanical Properties in Dog Rib. Journal of Bone and Mineral Research 2000; 15: 613-620.

[34] Wang X, Niehur GL. Microdamage propation in trabecular bone due to changes in loading mode. Journal of Biomechanics 2006; 39: 781-790.

[35] Boivin GY, Chavassieux PM, Santora AC, Yates J, Meunier PJ. Alendronate increases bone strength by increasing the mean degree of mineralization of bone tissue in osteoporosis women. Bone 2000; 27: 687-694.

[36] Chavassieux PM, Arlot ME, Reda C, Wei L, Yates AJ, Meunier PJ. Histomorphometric Assessment of the Long-term effects of Alendronate on Bone Quality and Remodeling in Patients with Osteoporosis. Journal of Clinical Investigation 1997; 100: 1475-1480. 
[37] Martin TJ, Sims NA. Osteoclast-derived activity in the coupling of bone formation to resorption. Trends in molecular medicine 2005; 11: 76-81.

[38] Lacy ME, Bevan JA, Boyce RW, Geddes AD. Antiresorptive Drugs and Trabecular Bone Turnover: Validation and Testing of a Computer Model. Calcified Tissue International 1994; 54: 179-185.

[39] Hazelwood S, Erickson A, Wang X, Allen M, Burr D, Martin B. Reduced Resorption Cavity Area in Canine Lumbar Vertebra Following Bisphosphonate Treatment. 55 ${ }^{\text {th }}$ Annual Meeting of the Orthopaedic Research Society; 2009 Feb 22-25; Las Vegas, Nevada: ORS; 2009, Abstract 315 .pg 38.

[40] Peter CP, Cook WO, Nunamaker DM, Provost MT, Seedor JG, Rodan GA. Effect of Alendronate on Fracture Healing and Bone Remodeling in Dogs. Journal of Orthopaedic Research 1996; 14: 74-79.

[41] Papapoulos SE, Determinants of bone strength and clinical practice; effects of bisphosphonates. Bone 2007; 41: S3-S7.

[42] Epstein S. The Roles of Bone Mineral Density, Bone Turnover, and Other Properties in Reducing Fracture Risk During Antiresorptive Therapy. Mayo Clinic Proceedings 2005; 80(3): 379-388.

[43] Boivin GY, Chazassieux PM, Santora AC, Yates J, Meunier PJ. Alendronate Increases Bone Strength by Increasing the Mean Degree of Mineralization of Bone Tissue in Osteoporotic Women. Bone 2000; 27(5): 687- 694.

[44] Allen MR, Burr DB. Changes in vertebral strength-density and energy absorptiondensity relationships following bisphosphonate treatment in beagle dogs. Osteoporosis International 2008; 19: 95-99.

[45] Beaupre GS, Orr TE, Carter Dr. An Approach for Time-Dependent Bone Modeling and Remodeling - Theoretical Development. Journal of Orthopaedic Research 1990; 8: 651- 661.

[46] Childs GV. Compact Bone Histology.University of Texas Medical Branch. 2003. <cellbio.utmb.edu/microanatomy/bone/compact_bone_histology.htm>.

[47] Velloso APB, Barbosa FRP, Farias MAC. Endocrinology. $<$ www.medstudents.com.br/endoc/endoc6.htm >.

[48] Equine Research Projects. Horserace Betting Levy Board. $<w w w . h b l b . o r g . u k /$ document.php?id=20>. 
[49] Rizzoli R, Greenspan SL, Bone G III, Schnitzer TJ, Watts NB, Adami S, Foldes AJ, Roux C, Levine MA, Uebelhart B, Santora AC II, Kaur A, Peverly CA, Orloff JJ. Two-Year Results of Once-Weekly Administration of Alendronate $70 \mathrm{mg}$ for the Treatment of Post menopausal Osteoporosis. Journal of Bone and Mineral Research 2002; 17: 1988-1996. 


\section{APPENDIX A: MATLAB CODE}

\%Bone Remodeling Simulation with Bisphosphonate Treatment

$\%$ modified from Jeffery Nyman

\%Emily Huang 7May2009

$\%$

clear

clc

\%\%\%\%\%\%\%\%\%\%\%\%\%\%\%\%\%\%\%\%\%\%\%\%\%\%\%\%\%\%\%\%\%\%\%\%\%\%\%\%\%\%\%\%\%\%\%\%\%\%\%\%\%\%\% \%\%\%\%\%\%\%\%\%\%\%\%\%\%\%\%\%\%\%\%\%\%\%\%\%\%\%\%\%\%\%\%\%\%\%\%\%\%\%\%\%\%\%\%\%\%\%\%\%\%\%\%\%\%\%

$\% \%$ Remodeling parameters \%\%



$\% \%$ Activation frequency conditions \%\%

$\%$ Describes Ac.f versus disuse and Ac.f versus damage curves \%
Acfmax $1=0.5$
$\%$ Maximum Ac.f due to damage
Acfmax2 $=0.5$
$\%$ Maximum Ac.f due to disuse
samax $=4.1905$
$\%$ Normalizes specific area
AcfdisO = 0.0;
$\%$ Equilibrium Ac.f for disuse
Acfdam0 = 0.0224693284;
$\%$ Equilibrium Ac.f for damage
AcfO $=(\text { Acfdam0 }+ \text { AcfdisO })^{*} \mathrm{saO} /$ samax ; \% Equilibrium Ac.f
$\mathrm{kb}=1100000000000000$;
$\%$ Remodeling coefficient (obtained from curve $\%$ fitting clinical data)
$\mathrm{kc}=\mathrm{phi0} / 2$
$\%$ Remodeling coefficient (obtained from curve $\%$ fitting clinical data)

\%\% Damage conditions \%\% 


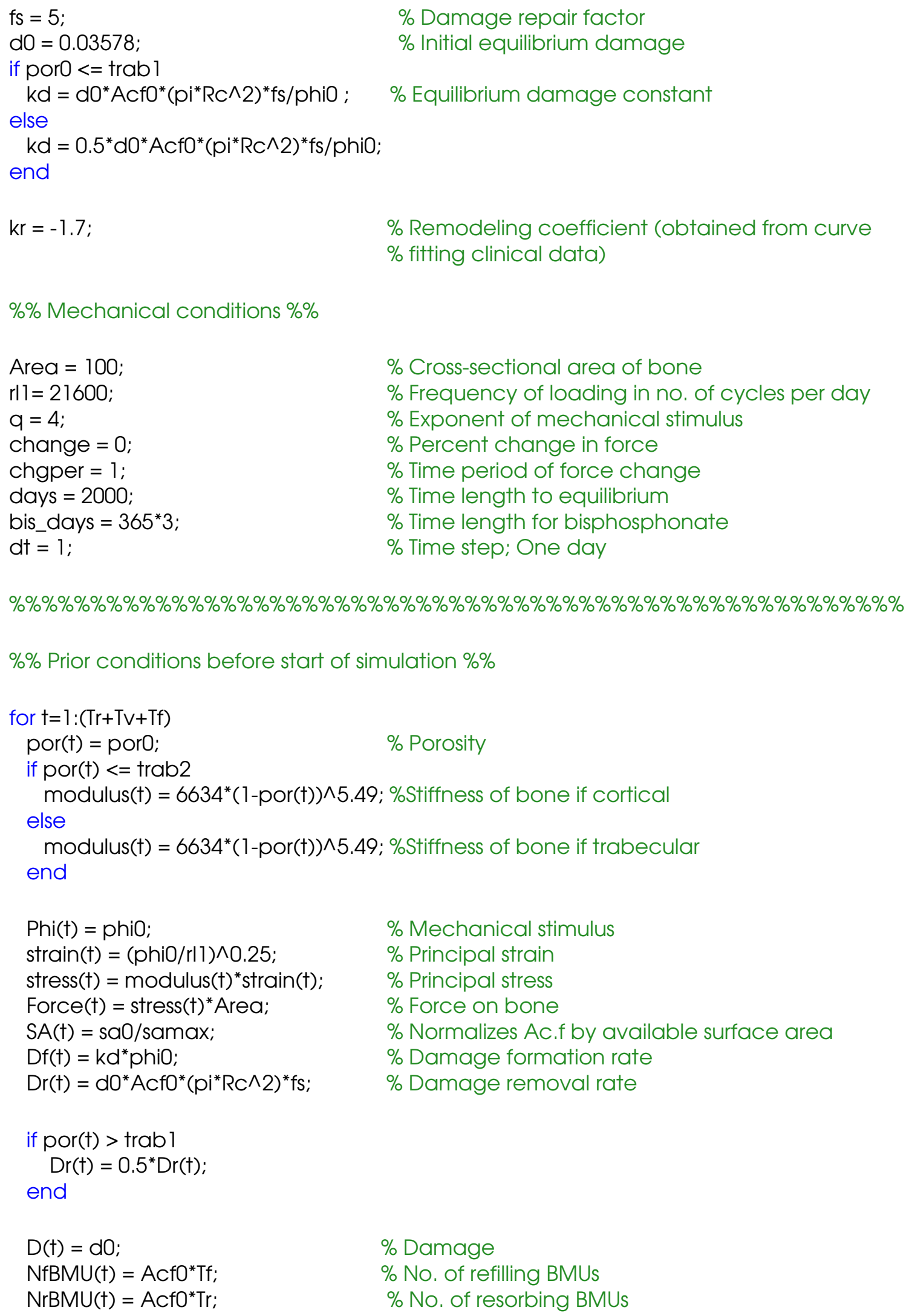




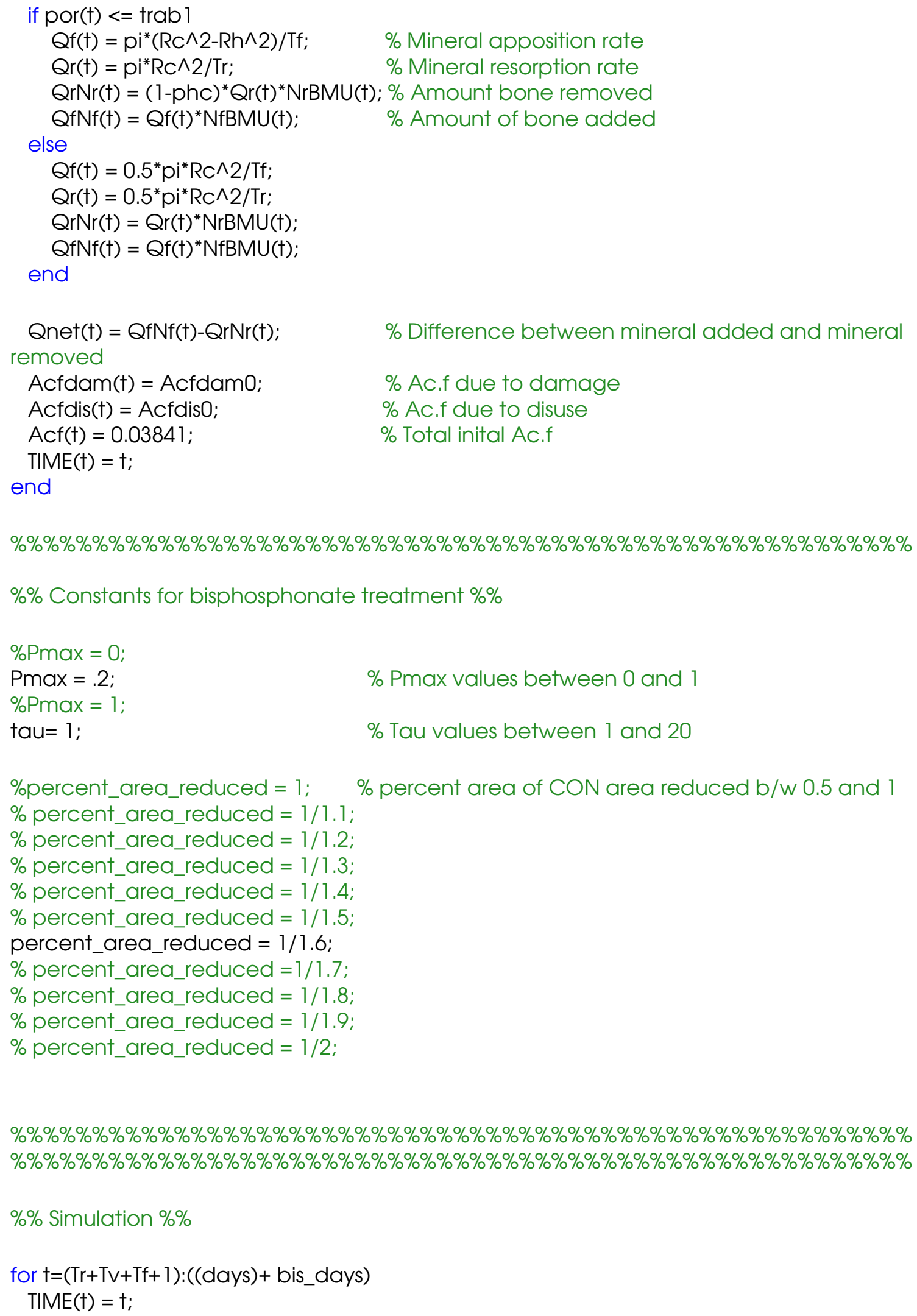

\%\%\%\%\%\%\%\%\%\%\%\%\%\%\%\%\%\%\%\%\%\%\%\%\%\%\%\%\%\%\%\%\%\%\%\%\%\%\%\%\%\%\%\%\%\%\%\%\%\%\% \%\%\%\%\%\%\%\%\%\%\%\%\%\%\%\%\%\%\%\%\%\%\%\%\%\%\%\%\%\%\%\%\%\%\%\%\%\%\%\%\%\%\%\%\%\%\%\%\%\%\%\%\%\%\%

$\% \%$ Simulation \%\%

for $t=(T r+T v+T f+1):(($ days $)+$ bis_days $)$

$\operatorname{TIME}(t)=t ;$ 


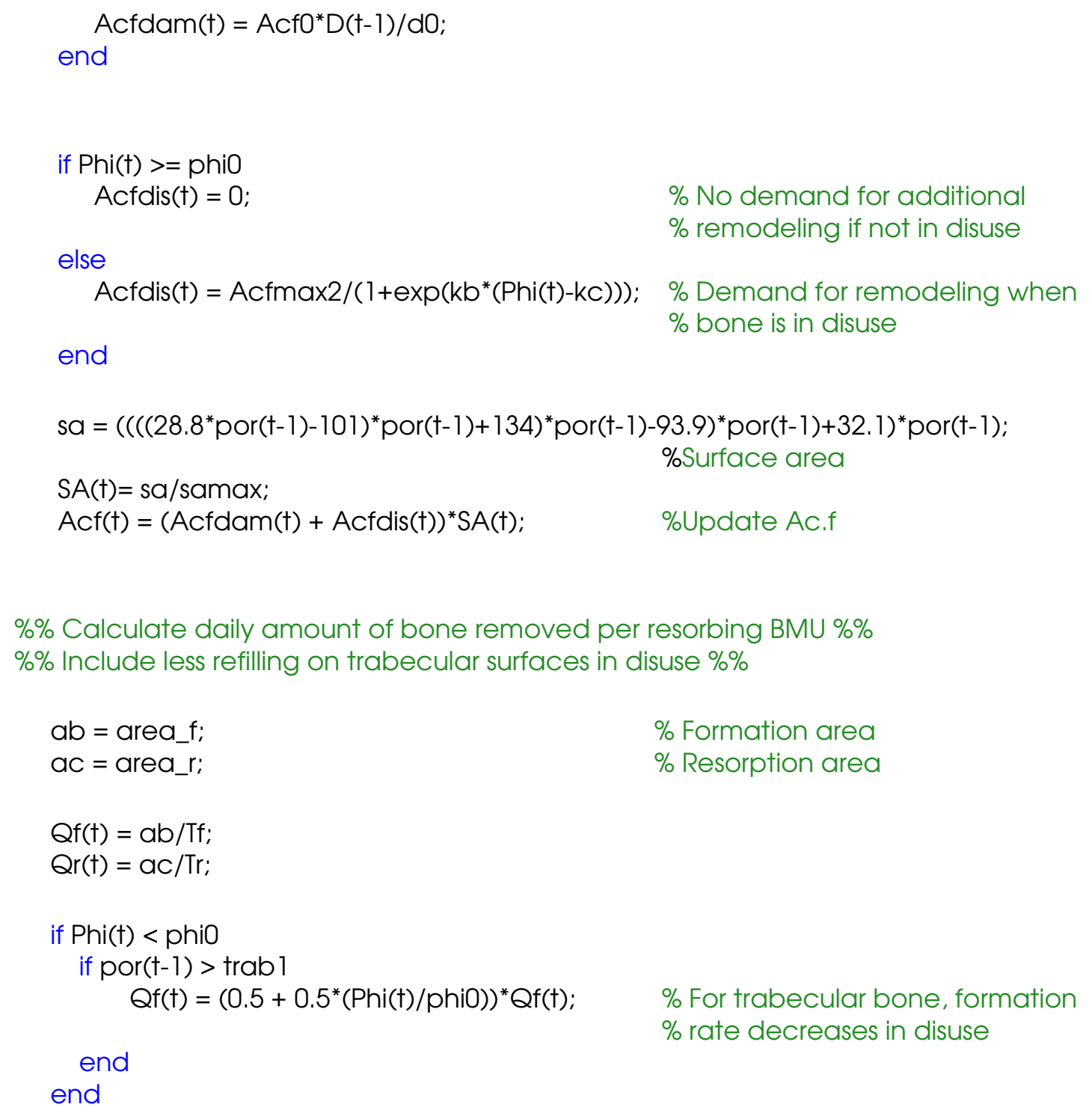




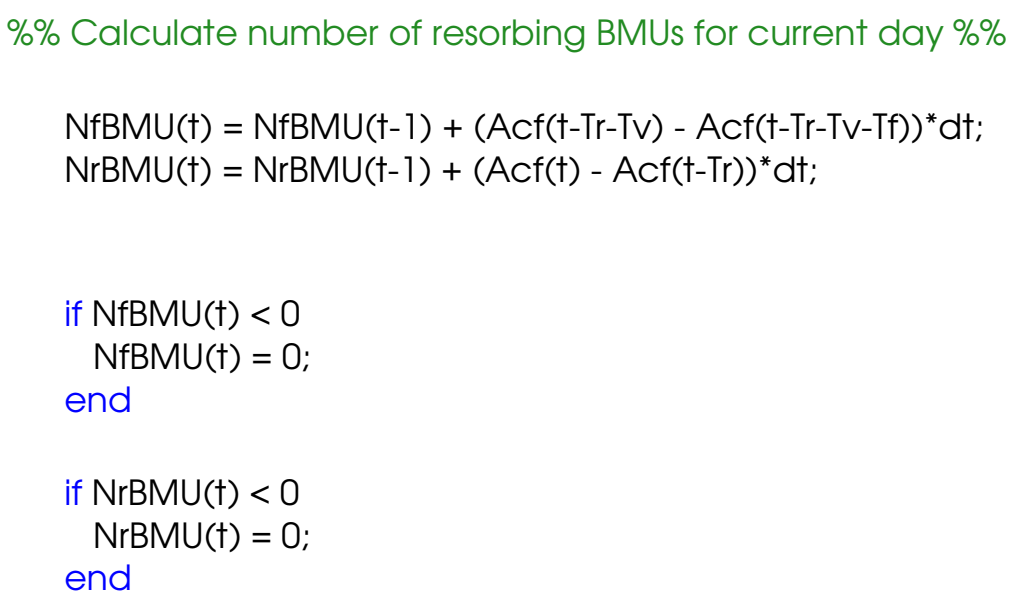




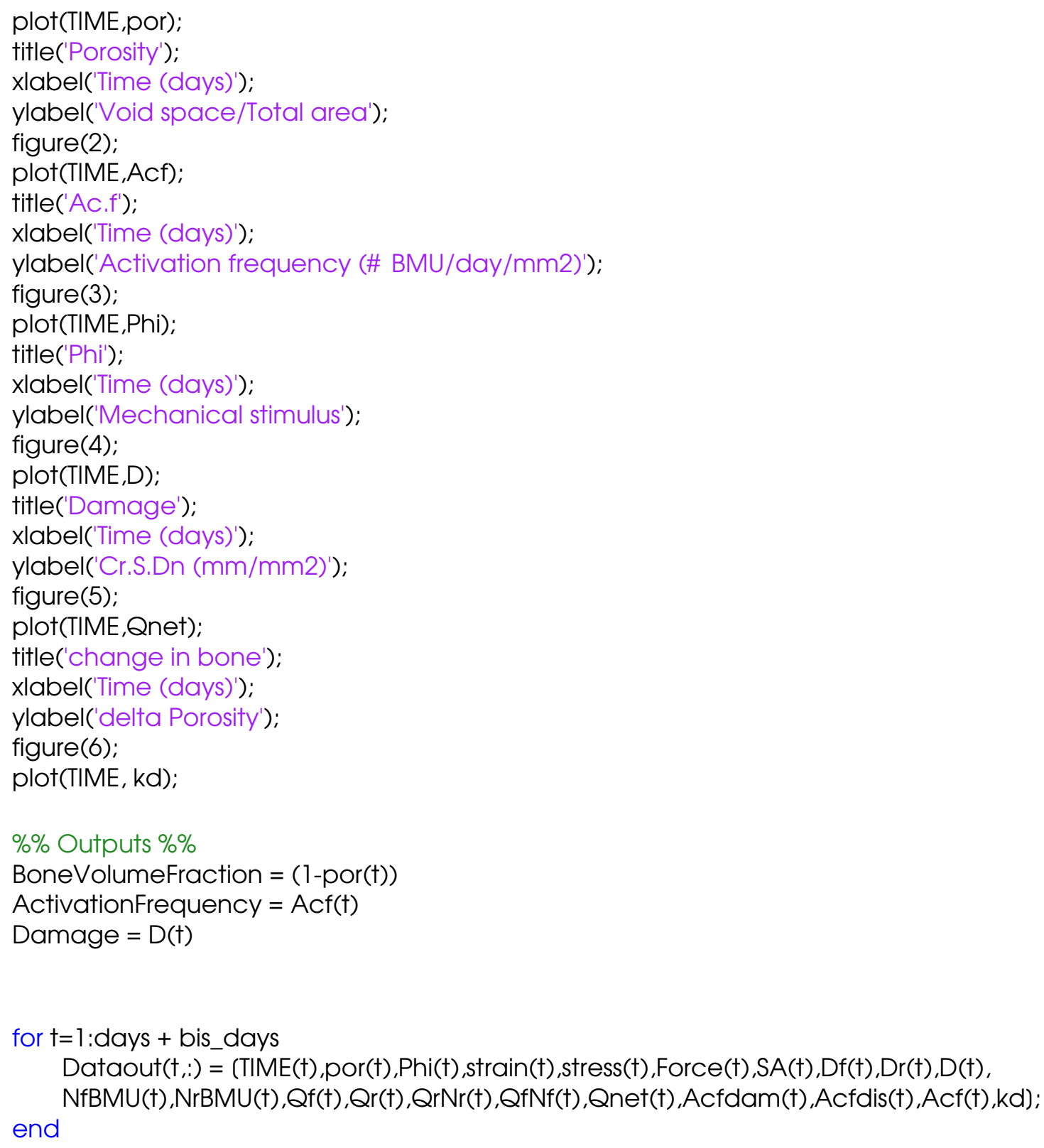




\section{APPENDIX B: COMPREHENSIVE TABLE OF ALL SIMULATED AND MEASURED DATA}

\begin{tabular}{|c|c|c|c|c|c|c|c|c|c|c|}
\hline & \multicolumn{2}{|c|}{ CON } & \multicolumn{2}{|c|}{ ALN0.2 (1 YEAR) } & \multicolumn{2}{|c|}{ ALN0.2 (3 YEARS) } & \multicolumn{2}{|c|}{ ALN1.0 (1 YEAR) } & \multicolumn{2}{|c|}{ ALN1.0 (3 YEARS) } \\
\hline & $\begin{array}{c}\text { Experimenta } \\
1\end{array}$ & $\underset{\text { d }}{\text { Simulate }}$ & $\begin{array}{c}\text { Experimenta } \\
1\end{array}$ & Simulated & $\begin{array}{c}\text { Experimenta } \\
1\end{array}$ & Simulated & Experimental & Simulated & Experimental & Simulated \\
\hline BV/TV & $\begin{array}{l}0.968 \pm \\
0.00489\end{array}$ & 0.9651 & $\begin{array}{c}0.966 \pm \\
0.00683\end{array}$ & 0.9649 & $\begin{array}{l}0.966 \pm \\
0.00683\end{array}$ & 0.9651 & $\begin{array}{l}0.964 \pm \\
0.00718\end{array}$ & 0.9649 & $\begin{array}{l}0.964 \pm \\
0.00718\end{array}$ & 0.9651 \\
\hline $\begin{array}{c}\text { Ac.f } \\
\underset{\substack{\text { (BMU's/mm } \\
\text { 2/day) }}}{ }\end{array}$ & $\begin{array}{c}0.0384 \pm \\
0.0290\end{array}$ & 0.0098 & $\begin{array}{c}0.0361 \pm \\
0.0322\end{array}$ & 0.009698 & $\begin{array}{c}0.00153 \pm \\
0.00215\end{array}$ & 3.6135 & $\begin{array}{c}0.0202 \pm \\
0.0134\end{array}$ & 0.009698 & $\begin{array}{c}0.00521 \pm \\
0.00792\end{array}$ & 0.01 \\
\hline
\end{tabular}

